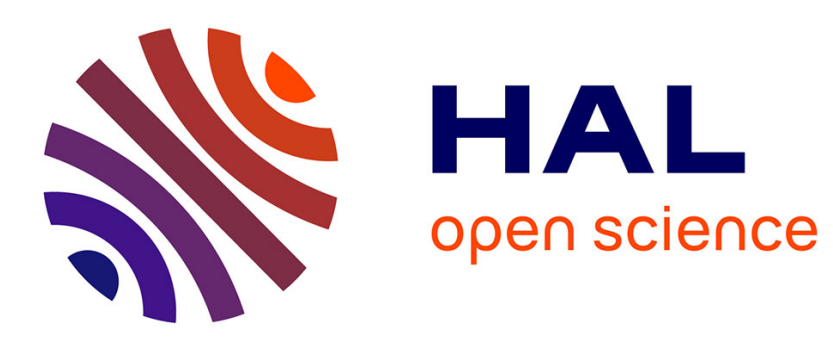

\title{
Transversal friction of epoxy-lubricated and dry carbon tows: From initial stages to stabilised state
}

\author{
Olga Smerdova, Omar Benchekroun, Noël Brunetière
}

\section{To cite this version:}

Olga Smerdova, Omar Benchekroun, Noël Brunetière. Transversal friction of epoxy-lubricated and dry carbon tows: From initial stages to stabilised state. Composites Part A: Applied Science and Manufacturing, 2021, 143, pp.106263. 10.1016/j.compositesa.2020.106263 . hal-03376152

\section{HAL Id: hal-03376152 https://hal.science/hal-03376152}

Submitted on 13 Oct 2021

HAL is a multi-disciplinary open access archive for the deposit and dissemination of scientific research documents, whether they are published or not. The documents may come from teaching and research institutions in France or abroad, or from public or private research centers.
L'archive ouverte pluridisciplinaire HAL, est destinée au dépôt et à la diffusion de documents scientifiques de niveau recherche, publiés ou non, émanant des établissements d'enseignement et de recherche français ou étrangers, des laboratoires publics ou privés. 
Transversal friction of epoxy-lubricated and dry carbon tows: From initial stages to stabilised state

\author{
$\underline{\text { Olga Smerdova }^{1 *}}, \underline{\text { Omar Benchekroun }^{1,2}}, \underline{\text { Noel Brunetiere }}$ \\ ${ }^{1}$ Institut Pprime, CNRS, ISAE-ENSMA, Université de Poitiers, Futuroscope Chasseneuil F-86962, France \\ ${ }^{2}$ Present address : Ecole Centrale de Casablanca, Bouskoura, Ville Verte, 27182, Maroc. \\ *Corresponding author olga.smerdova@ensma.fr
}

\title{
Abstract
}

An experiment was designed and carried out to study the friction and deformation of carbon fibre tow under sliding transverse to the orientation of the fibres. A continuous frictional force was measured in reciprocal sliding tests over a sliding length of about one width of the tow, using incremental tests of 4 $\mathrm{mm}$ of sliding with a stop after each millimetre to measure the topography of the tow in contact with a glass plate. Although the friction coefficient depended on the initial state of the tow in the first millimetres of sliding, this effect tended to disappear with sliding distance under both dry and epoxylubricated conditions. Four stages of friction were identified and related to their underlying mechanisms: internal stress relaxation, shear deformation of the tow and microslips at the interfaces, macroslip of the external interfaces, and force relaxation after the end of glass sliding.

\section{Introduction}

Carbon fibre tows are used as reinforcements in polymer matrix composites and can be arranged in 2D fabrics and 3D architectures. During manufacturing, such as in the resin transfer moulding process, dry tows are woven and compressed with a tool to shape them in a preform, which is then impregnated with liquid resin and solidified by curing. In other processes, such as thermostamping, the fabric is impregnated before shaping and solidification. In both cases, the friction between the tow and the tool is responsible for the correct positioning and for maintaining in place the whole reinforcement architecture.

The mechanics of tows, which are composed of thousands of rigid but very thin fibres, is complex and involves both the internal friction between the fibres and the mechanical properties of the fibres themselves. The tows are highly flexible under transversal and torsional loading, where internal friction plays a crucial role, but very stiff under longitudinal tension, which is defined by the stiffness of fibres. The friction between individual carbon fibres has been measured only in a limited number of studies [1- 
4]. The relationship between the frictional and normal forces is not usually linear, and the frictional behaviour depends on the type and size of the fibre.

Compared to the individual fibres, the friction of a carbon fibre tow is easier to measure but more difficult to explain and to model. However, there is growing interest in such measurements, as highlighted by recent publications on this topic [5-13]. The friction between a carbon tow and a tool was measured by Cornelissen et al. [6], using a tow in a contact with a smooth and a rough cylinder, and later by Mulvihill et al., with a smooth [9] and a rough [10] plane; in the latter set of experiments, it was found that the coefficient of friction of a carbon tow was twice as high against a smooth metallic counterface (with an arithmetical mean deviation of the roughness height, $R_{q}=0.02 \mu \mathrm{m}$ ) than the rough one $\left(R_{q}=1.1 \mu \mathrm{m}\right)$. This result was confirmed in a later, more extensive study [10] with a range of $R_{a}$ for a metallic counterface of between 0.005 and $3.2 \mu \mathrm{m}$. A power law between the friction force and the normal load was measured under all the conditions studied.

In the experiments cited above, the orientation of sliding (and thus the frictional force) was parallel to the fibres. This arrangement is favourable for these measurements, since the longitudinal rigidity of the fibres is high and the relative movements of individual fibres induced by sliding are rather limited. The tow can therefore be regarded as an elastic solid with approximately constant surface roughness during sliding. This representation and the adhesive model of friction formed the basis of several contact models for carbon tows. In these models, the frictional force is proportional to the real contact area, with a shear strength parameter that describes the shear resistance of the junctions formed between the two surfaces at the real points of contact. The first contact mechanics model of the friction of a carbon tow against a rough metallic counterface was developed by Cornelissen et al. [5]. The rough surface was represented as covered with smooth elastic spheres of equal radius, with a Gaussian height distribution, while the carbon tow was modelled as a rectangular box of ideally packed elastic cylinders. This hypothesis of the ideal packing of parallel fibres in a tow was later revealed to be far from reality [8], and optical measurements by Smerdova et al. [7, 8] and Mulvihill et al. [9] demonstrated that the real contact area was only a few percent of the apparent one, for both a fabric and an individual tow. Similar models of adhesive contact with ideal packing of fibres in a tow were used to explain the experimentally observed dependency of friction on the angle between two carbon tows $[9,12,13]$. The measured friction coefficient was significantly higher in a parallel arrangement than a perpendicular 
one, with a very rapid decrease between $0^{\circ}$ and $10^{\circ}$, and almost no further change up to $90^{\circ}$. The explanation based on the contact models is that there is a higher contact area between long parallel

cylinders than crossed ones. Moreover, Tourlonias et al. [13] repeated the same experiment using a tow and a single carbon fibre, and measured a smooth decrease in the coefficient of friction of a fibre, from 0.15 at an orientation of $10^{\circ}$ to 0.11 at $90^{\circ}$. Although most of these studies discussed the possible rearrangement of fibres during sliding as one of the reasons for the lower friction in the perpendicular orientation, none of them measured this effect or tried to take it into account within a contact model.

A recent study by Dackweiller et al. [14] revealed that the frictional coefficients of a dry carbon tow in transversal and longitudinal orientations to sliding were significantly different, and were dependent on the counterface material. Two cases were observed: one in contact with aluminium plate where the transversal friction was higher than the longitudinal one, and the other with a solid epoxy-covered plate with the opposite relation. The explanation suggested by the authors was based on the relationship between the cohesion and adhesion between the tow and the counterface, or in other words, the internal and external friction. When the adhesion between the fibres is higher than the adhesion between the fibres and the counterface, transversal sliding provides a smaller friction force than longitudinal sliding. In this case, the measured (apparent) friction coefficient does not actually represent the friction at the external interface. Considering the differences observed between the transversal and longitudinal friction of the tow and the lack of experimental evidence for the mechanisms underlying this difference, the primary aim of the present paper is to design and conduct an experiment that can help to clarify this point.

The mobility of the fibres is often as assumed to be responsible for the variation in the frictional behaviour during each sliding pass and between the cycles. For example, Tourlonias et al. [2, 13] measured high variations in the friction coefficient in parallel orientation, with a global increase from 1 to 1.7 between the first and the 15th cycles, and then a further decrease with relative stabilisation at 1.5 around the 80th cycle. The decrease in the friction coefficient was significantly smaller but also present for other orientations. For instance, in the same experiment with a perpendicular orientation [13], it dropped from around 0.24 to 0.2 in the first 10 cycles, and then stabilised at this value. The decrease with an increasing number of cycles was even more significant (from 0.27 to 0.16 ) in another experiment by the same group [2]. It is clear from these studies that experimental evidence is lacking 
that can explain the variation in the frictional behaviour of the tows with sliding distance and with the number of cycles. Providing this evidence based on direct observations of the tow surface during sliding is the second aim of the present paper.

When it comes to studying the friction of carbon tows or fabrics impregnated with liquid polymer, the mechanisms are rather different and have been less frequently studied. A number of studies $[15,16,17$, $18,19]$ have measured the friction coefficients of large 2D fabrics lubricated with liquid polymer. The resulting friction coefficients are usually plotted as a function of the Hersey number, which is itself a function of the normal load, sliding velocity and viscosity of the liquid. A measured linear increase in the friction coefficient of a fabric in these curves is associated with the hydrodynamic lubrication, as a lubricant layer is constantly present everywhere between the tow and the counterface. A benchmark exercise [20] was carried out in seven research laboratories to compare the friction results for pieces of the same commingled glass-polypropylene fabric under dry and polymer-lubricated conditions. The results revealed rather significant differences in the measured frictional behaviour, which were related by the authors to the experimental setups used. These discrepancies highlight the importance of understanding the local mechanisms in order to explain the global behaviour of a fabric and to be able to reproduce it.

Ten Thije et al. [15] developed a lubrication model at the scale of the tow, in which the cross-section of the tow was perfectly elliptical and covered with microscale roughness, due to the use of parallel fibres with ideal packing. The permeability and deformability of these bundles were assumed to be negligible, and were not taken into account. According to the authors, the results showed that the response was mostly governed by the geometrical features of the tow in the region of minimum film thickness. Since these measurements were not reported in this study and were not available in the literature, the model was validated by comparing the friction coefficient with the results of experiments on a 2D fabric. Given the highlighted importance of the real shape of the tow in terms of sliding and the current absence of any experimental measurements on lubricated tows, the third aim of the present paper is to carry out frictional experiments on a lubricated tow and to study its deformation and displacement due to sliding, relating them to the variations in the frictional force.

It should be noted that this last aim is rather ambitious, and that only an initial contribution to this understanding will be presented here. The behaviour of a lubricated tow under only transversal 
compression, a first step before sliding, has been the subject of only a few previous studies [21, 22].

Dharmalingham et al. [21] measured the shape of lubricated and dry tows under transversal compression and found that the Poisson's ratio, densification, and flattening were influenced by the initial shape of the tow, the compressive load and the lubrication. Lubricated tows were found to be less compressible than dry ones, since they flatten without densification. However, this difference was more pronounced for a glass fibre tow than a carbon fibre tow. Latil et al. [22] used X-ray microtomography to investigate the transversal compression of a model tow composed of fishing line fibres and lubricated with olive oil. A microrheometer was placed in a beamline at the European Synchrotron Radiation Facility in order to enable quick scans of about a minute at each compression step. These in situ images were used to characterise the microscopic and mesoscopic deformations of the tow. Although the large diameter of $150 \mu \mathrm{m}$ and the flexibility of the PVDF fibres were not comparable to those of carbon fibres, this study highlighted the micromechanisms that define the mesoscopic compression behaviour of the tow. The results revealed that in the compressed state, the number of contacts between fibres increased, while the mean contact length of each contact decreased. The compression induced bending and enhanced the disorientation of fibres.

The three aims of this work set out above are achieved by designing an experimental setup that enables in situ observation of the transversal frictional behaviour of a carbon tow. The setup and the experimental procedure are discussed in Section 2 of this paper. The first set of results is presented and discussed in Section 3.1, and contains the average kinetic friction coefficients of dry and lubricated tows during each forward and backward pass of four sliding cycles. To investigate the mechanisms behind these average values, the mechanical loading on the tow and the origins of the measured friction force are discussed in Section 3.2. A model based on the mesoscopic shear mechanics of the tow and adhesive friction theory is suggested to explain each evolution of the measured friction force. The subsequent sections describe another set of experiments that involve sliding in increments of $1 \mathrm{~mm}$ and imaging of the tow surface before and after each increment by a 3D microscope. Section 3.3 presents the measurements of the initial shape of lubricated and dry tows after transversal compression but before sliding. The evolution of the friction coefficients with sliding increments and a comparison with the results of reciprocal sliding tests are presented in Section 3.4. An analysis of the contributions of the different mechanisms discussed in Section 3.2 to the measured values of the friction coefficients is given in Section 3.4. Finally, the results of 3D measurements of the tow surfaces before and after each 
increment are presented in Section 3.5, and the differences between dry and epoxy-lubricated behaviour are discussed.

\section{Materials and Methods}

\subsection{Materials}

The tow used in this study was the same as that used by Mulvihill et al. in their work on the longitudinal friction of a tow [9]. It was a T700SC-12k-60E with a average diameter of $6.7 \mu \mathrm{m}$ for the carbon fibres, a small amount of sizing to enhance the compatibility with epoxy, and around 12,000 fibres in a tow. The resin used to lubricate the tow was EpoFix epoxy resin by Struers. The viscosity given by the manufacturer was $600-800 \mathrm{cP}$ at $250^{\circ} \mathrm{C}$. Since the resin was used without hardener, at room temperature and with humidity regulated by air conditioning, no change in the properties was expected over time.

\subsection{Experimental apparatus}

A new experimental device was designed and assembled to combine the measurements of friction force in sliding contact under a constant normal load with microscopic observation of the structure of the tow. The apparatus is schematised in Figure 1 and illustrated in Figure 2a. A micrometric screw fixed onto the microscope stage is used to impose displacement manually onto the glass plate sliding on the carbon fibre tow in transversal orientation. The glass plate of $17.5 \times 17.5 \mathrm{~mm}$ embedded into a metallic part visible in Figure 2a serves as a window for microscopic observations. The metallic part is pushed and pulled by the micrometric screw. Between them are an S-shaped tension/compression load cell from Futek with a load capacity of $\pm 8.89 \mathrm{~N}$, which enable to measure the friction force, and a thin elastic beam designed to allow some vertical flexibility and to compensate for the gap due to the change of thickness of the tow. The elastic beam has a significant axial stiffness to avoid interfering with the measured friction force. The normal load on the tow/glass contact is applied through a weight suspended below the microscopic table on a plate joined to the top glass plate around the microscopic table. The carbon tow is clamped onto the bottom octagonal plate visible in Figure $2 \mathrm{a}$ and $\mathrm{b}$. This plate, containing a glass window in the area of sliding, is fixed onto the microscope table. The free length of the tow between the clamped ends is $90 \mathrm{~mm}$. 


\subsection{Setting up the experiment}

Before each experiment, the glass plates were dissociated from each other and cleaned with acetone to

remove any residual material. The lower plate was then covered with silicone paper using sticky tape, to make it visible through the microscope. A new piece of tow from the same spool was taken for each experiment.

To apply the pre-tension, the tow was fixed at one of its ends with the clamping plate, while the moving part was removed from the setup. Particular care was taken to avoid touching the "useful" part of the tow while unrolling it from the spool. Once the first end had been fixed, a piece of sticky tape was placed on the opposite side of the tow. Pre-tension was applied using a hanging weight attached by the tape to the free end of the tow. Two masses of 100 and $500 \mathrm{~g}$ were used for the pre-tension in this study. Next, the second end of the tow was fixed with the clamping plate, and the surplus part of the tow was cut off. In the lubricated tests, $1 \mathrm{ml}$ of epoxy was poured onto the central part of the tow using a syringe. The upper support with the glass window was placed onto the tow, and care was taken not to apply any initial shear.

The compression load was applied by a mass of $500 \mathrm{~g}$ suspended beneath the lower plate, as shown in Figure 1 and Figure 2. This mass, together with the weight of the top glass support, provided a load of 6.55 N. The nominal pressure at the contact depended on the width of the tow, and was $93.5 \mathrm{kPa}$ for a tow of width $4 \mathrm{~mm}$ and $31.2 \mathrm{kPa}$ for width $12 \mathrm{~mm}$.

\subsection{Experimental procedure}

Two sets of experimental investigations were carried out. In the first set, the focus was solely on the frictional forces. In this case, the sliding distance was up to $8 \mathrm{~mm}$ and the movements were in forward and backward directions. In the second case, we were interested in both the frictional forces and the evolution of the tow surface via microscopic observations at the same time. In this case, the top glass plate was only pushed by $4 \mathrm{~mm}$.

\section{a. Reciprocal sliding tests}

To achieve the maximum possible sliding distance, the right-hand edge of the top glass plate was lined up with the right-hand edge of the tow before the experiment. Sliding was applied until the left edges of the glass plate and tow coincided. For each tow, up to 10 sliding cycles were applied. The upper plate 
was pushed and pulled through a range of about 5.5 to $8 \mathrm{~mm}$, depending on the initial width of the tow, by the manual micrometric screw in each cycle.

\section{b. Incremental tests}

When the setup was placed under the microscope, the first microscopic 3D image of the tow was taken. A displacement of $1 \mathrm{~mm}$ was imposed using the manual micrometric screw. The friction force was recorded during the displacement and after stopping, until the force value had stabilised. Once the force had been stabilised, the force sensor was turned off and the microscopic measurements were made. The upper plate support was displaced with a speed that was as constant as possible, of around 0.2 $\mathrm{mm} / \mathrm{s}$. This procedure was repeated four times. The last topography measurement was performed before the last sliding increment.

3D measurements were made with an Alicona Infinite Focus microscope. This microscope takes optical images at different heights with a very small vertical step, and reconstructs the 3D topography of the object based on the best focus position of each pixel. The measurements presented in this study were performed at a magnification objective of $x 5$, which gave a lateral resolution of $3.457 \mu \mathrm{m}$ per pixel and a vertical resolution of $0.41 \mu \mathrm{m}$. The images were then stitched using the microscope software, so the whole surface of the tow in contact with the glass window could be measured. The recorded images were analysed to quantify the width, displacement and roughness of the tow.

\subsection{Post-processing of topography images}

The raw topography measurements, with no correction or rectification, were saved as 16-bit images with a resolution per grey value of about $2 \mathrm{~nm}$, i.e. significantly lower than the resolution of the microscope. The absolute $\mathrm{XY}$ position of each image was also recorded in order to trace the displacement of the tow. In the case where epoxy was used to lubricate the contact, the height measurements were corrected by the refractive index of epoxy, which was taken as 1.6. To obtain this index, the topography measurements were made with the same microscope configuration on a Vshaped notch both with and without epoxy, and the change in the measured slope of the notch was then quantified.

The topography images were then analysed with Matlab software to characterise the roughness, deformation and displacement of the tow. An image analysis algorithm was developed to select the surface of the tow from the image, remove the background and calculate the necessary parameters. An 
example of the surfaces measured for a lubricated tow is shown in Figure 3. It can be seen that the curvature of both edges of the tow is not significantly changed after sliding, but a change in its width is visible between the start of the test and after $3 \mathrm{~mm}$ of sliding. There is a slight debonding of the fibres on the right side of the tow, and this effect was present in all the tests to some extent. The figure shows that the height of the tow surface is less than $300 \mu \mathrm{m}$ in all cases, although hills and valleys with amplitudes of up to $100 \mu \mathrm{m}$ are seen on the bottom surface, which seems unlikely since this surface is a plane. It seems that despite the use of silicone paper under the tow, the lower surface was not captured well by the microscope. To avoid possible errors, the tow surface was analysed with respect to the upper glass plate rather than the lower one. Since the glass plate was transparent, it was not visible with the microscope, and an algorithm was therefore written to find its most likely position. A mean profile was created by averaging the central part of the tow over a width of $3.457 \mathrm{~mm}$ in the $y$ direction. An example of the obtained profile is shown in Figure 4. First, a large number of straight lines with different slope angles and vertical positions were examined as possible locations of the upper glass plate. For each line, the distance $d$ was calculated for all the points of the tow profile. Finally, the line with the highest number of profile points closer than $10 \mu \mathrm{m}$ that did not cross the profile was considered as the actual position of the upper glass plate.

The set of distances $d$ calculated for each profile point between the glass plane and the tow surface was then averaged and normalised based on the tow width $w$ at the current sliding increment, in order to calculate the roughness parameter $\bar{d}$, as follows:

$$
\bar{d}=\frac{\sum d \times w_{p}}{w}
$$

where $w_{p}$ is the pixel width.

\section{Experimental results and discussion}

\subsection{Reciprocal sliding tests}

Reciprocal sliding tests were first carried out on the carbon tow, both with and without epoxy. In these tests, the axial pre-tension of the tow was 500g. Four to ten friction cycles were performed on each tow in order to study the evolution of the frictional behaviour over time and with repeated sliding. In total, four tows were tested in dry conditions and four in epoxy-lubricated conditions. The maximal sliding distance varied between 5.5 and $8 \mathrm{~mm}$, and was limited by the difference between the width of the sliding glass plate and the initial width of the tow. The frictional force was measured continuously during 
the forward and backward sliding steps. The experiment was paused for a few minutes after each forward and backward sliding movement, in order to study the eventual force relaxation.

The frictional data for these tests and for the incremental tests are presented in the Supplementary Material. A careful examination of the first sliding pass reveals rather significant differences in the evolution of the friction force, as can be seen from Figure 5. In this figure, the instantaneous friction coefficient, which is a ratio of tangential and normal force, is presented as a function of glass sliding distance calculated by dividing the total sliding length of each pass by its duration. This representation is not exact, since during the breaks between turns of the micrometric screw, the sliding distance is shown to change; however, it gives a good idea of the evolution of the friction coefficient with distance and allows us to compare it with incremental tests, which are also shown in this figure and will be discussed later. The duration of each small break was around $0.5 \mathrm{~s}$.

The evolution of the friction coefficient with sliding distance was qualitatively and quantitatively different between the epoxy-lubricated and dry tests. In dry conditions, while tows 1 and 4 revealed a slight increase in the friction coefficient in the first millimetres of sliding, tows 2 and 3 showed a decreasing friction coefficient with sliding distance after an initial increase to significantly higher values. At the end of the sliding distance, the differences in the friction coefficient between the tows tended to disappear. It is noteworthy that after the first pass, all the tows tested in dry conditions showed behaviour that was similar to the first pass of tow 3, i.e. an increase in friction during the first millimetre of sliding, and then a smooth decrease until the end of the sliding distance. The other sliding passes are presented in the Supplementary Material. Similar behaviour was also observed during the backward sliding movement from the first cycle, for all the tows tested in dry conditions.

In contrast to dry sliding, epoxy lubrication tended to increase the friction coefficient with sliding distance in all of the tows. The slope of this increase was different between the four tows. Figure 5(b) shows that the behaviour changed after first couple of millimetres of sliding. In the further passes in forward direction, all the tows showed behaviour similar to that of tow 1 and 3 in Figure 5(b), with constant friction in the first one or two millimetres and then a linear increase until the end of sliding. This behaviour was reversed in backward sliding, and the friction increased linearly from the beginning and became constant over the last one or two millimetres. 
Table 1 shows the average values of the kinetic friction coefficients between all tows, for each forward and backward pass in each set of conditions. The friction coefficient was calculated for the last $3 \mathrm{~mm}$ of glass sliding in each test, and took into account only the actual phases of sliding, without the reduction in force during the short breaks. The average value for all passes and all tows is shown in the last row of this table.

The first observation is that the reproducibility of these results are rather good, considering the large differences between the initial states of the tows. The standard deviation for the average of all the tests and passes was around $10 \%$ for each condition. The mean friction coefficient value between the tests was constant with an increasing number of cycles, meaning that repeated sliding of the glass in the backward and forward directions did not significantly alter the frictional behaviour. However, the standard deviation between the four tows tended to decrease with an increasing number of cycles. This demonstrates that the differences in friction between the tows due to their initial state tend to disappear with sliding, and their frictional behaviour becomes more and more uniform as the cycles progress.

As expected, the friction coefficient in the dry condition was higher than the epoxy-lubricated condition. However, there was a difference in the friction coefficients between the forward and backward movements in both cases. In dry conditions, the friction coefficient was higher during the forward movement than on the return, while it was higher in backward sliding in the epoxy-lubricated condition. This might be due to alterations in the static friction threshold after forward sliding, which is related to the surface state of the tow. In the case with epoxy, the time- and history-related viscoelastic effects could also have contributed to the change in the friction coefficient during the backward motion. In addition, a possible difference in the relative slope between the glass plate and the top surface of the tow during the backward and forward motion could lead in changes in the lubrication conditions and the friction.

\subsection{Analysis of mechanical loading on the tow and the origins of the friction force}

Since we are interested in the evolution of the frictional force from the initial stages to a stabilised state, a scrupulous analysis of the force signal is necessary in order to associate variations in this force with physical mechanisms. A schematic of the evolution of the measured force during each sliding increment, corresponding to one turn of the micrometric screw, is shown in Figure 6(a). This type of force evolution 
was observed in both dry and epoxy-lubricated conditions (see Figure 5), with the only difference in the relative position being between points F3 and F4. Four stages can be distinguished on this graph, and are repeated during sliding.

To explain the evolution of the friction force, an analysis of the mechanical loading on the tow is required. Figure $6(\mathrm{~b})$ shows a free body diagram of the cross-section of the tow, compressed between the fixed lower plane and the upper plane under sliding. A displacement with constant speed is applied to the glass plane, which shares an interface with the top of the tow. Due to adhesion at this interface, an interfacial force $F_{\text {ext1 }}$ grows and resists the shear (slip) of the tow at this interface until the shear strength of all the microjunctions is reached. This force, which is external to the bulk of the tow, deforms the cross-section and tends to displace the tow. However, it is balanced by a second interface at the bottom of the tow, where a second interfacial force due to adhesion $F_{\text {ext2 }}$ also grows. Both interfacial forces are applied outside the centroid of the cross-section of the tow, and create a torsional moment within the tow, resulting in shear deformation. However, since the tow is fixed at its ends by clamped plates, any deformation or displacement of its cross-section is restricted by its bending rigidity. The two interfacial forces must be balanced by the bending force (represented as an elastic spring and $F_{b}$ on the sketch), which is proportional to the displacement of the centroid of the cross-section.

The contribution of the internal friction (shear of the tow) and the external friction at the two interfaces to the measured force is controlled by the shear strength of the interfaces between the carbon fibres and the glass. The friction coefficient of the carbon fibres used in this analysis was measured by Mulvihill et al. [9] and was found to be dependent on the normal pressure (and ultimately on the real contact area). Since in our experiment, the width of the tow varied between 4 and $12 \mathrm{~mm}$, the nominal normal pressure was between 30 and $90 \mathrm{kPa}$. Within this range, friction coefficient decreased from 0.45 to 0.3 for the tow/glass contact and from 0.28 to 0.24 for the tow/tow parallel contact. The latter can be compared with the internal friction between the parallel fibres inside the tow. These results show that the internal friction threshold of the carbon fibre tow must be lower than that at the interface with the glass, which will favour intratow slip and deformation before sliding against the external interfaces.

Based on this analysis, the measured friction force pattern depicted in Figure 6(a) can be explained by the following stages of stick and slip between the two interfaces and inside the tow. 
After compression or shear of the tow, a transversal movement can free certain fibres and relax internal stresses. This initial rearrangement of the fibres creates a drop in the measured force and a displacement of the tow without resistance. A drop was observed in all tests at the onset of sliding and at each break between rotations of the micrometric screw.

\section{Second stage, F2-F3: Shear of tow, no macroslip at either interface}

In this stage, the tow is stuck to both interfaces and is sheared by the applied displacement of the upper interface. The measured force grows rapidly with the displacement of the glass, and represents the shear resistance of the tow (due to internal friction between fibres and the elastic deformation of the tow). Both interfacial forces grow with time due to the shear resistance of the micro-junctions between the two surfaces. This phase lasts until all the micro-junctions at one of the interfaces are broken.

Third stage, F3-F4: Slip at one or both interfaces

The force necessary to begin the macroslip of an interface depends on the number of micro-junctions (the real contact area) and the shear strength of each (the material parameter). Since there is no reason for the real contact area to be same at both interfaces, the slip will not start at both interfaces at the same time. If the lower interface is the first to slip, the tow stays stuck to the upper glass plate, and they move together with the imposed constant speed. If the upper interface is the first to slip, the tow is stuck to the lower plate. In both cases, the tow continues to deform due to the difference in the direction between the two interfacial forces (torsion) and the resistance to bending. This deformation, which results from local movements of the individual fibres, modifies the real contact area of the interfaces during sliding and can create sliding (stick-slip) instabilities.

It is likely that at some point, the deformation of the tow with sliding will end due to the balance between frictional forces at the interfaces and the bending force. From this time onwards, the two interfacial friction forces are equal. The tow is rearranged so that each fibre is in balance between the contact forces (with other fibres or with one of the two interfaces) and the elastic bending force. The measured force does not vary during sliding.

\section{Fourth stage, F4-F5: End of slip, elastic recovery}

When the applied sliding stops, the elastic deformation incurred in the tow tends to recover. Due to the complex internal structure of the tow, retardation of this recovery is possible, which is ascribed to 
viscoelastic behaviour. This recovery is limited by the static friction limits of both interfaces and between the fibres themselves. Microjunctions are formed again and both interfaces are stuck until the next cycle of glass sliding.

When the tow is lubricated by a liquid epoxy, the adhesion plays a role only in the case of mixed lubrication. The microcontacts between fibres and at both interfaces external to the tow slip more easily, resulting in the generally lower friction coefficients seen in Table 1 . Moreover, due to the viscosity of the resin, viscoelastic behaviour of the tow is expected.

According to our analysis, there are distinct contributions from two phenomena to the friction coefficient measured during glass sliding, as shown in Figure 5 and Table 1 . The first can be attributed to the internal shear of the tow and the shear of micro-junctions at the external interfaces $\mu_{\text {int }}$ without macroslip (rupture and sliding of all micro-junctions), which corresponds to stage 2 in Figure 6(a). The second contribution is from the constant change in the shape of the tow and the surface described in stage 3 above, and thus the internal and external contact area and the local thickness of the lubricant during macrosliding between the glass and tow $\mu_{\text {ext }}$.

$$
\mu=f\left(\mu_{\text {int }}, \mu_{\text {ext }}\right)
$$

\subsection{Variability in the initial shape of tows}

Despite the care that was taken during manipulation of the tows before sliding, microscopic observations revealed that their initial shapes after axial pre-tension and compression varied significantly. Although this contributed to the dispersion in the results, it facilitated an understanding of the mechanisms behind friction.

In the initial state under axial tension, the cross-section of the tow is not necessarily symmetric with respect to its middle line. This misalignment is amplified when a glass plate is placed onto the tow and compression is applied. A slope $\alpha$ of the order of $1^{\circ}$ between the glass plane and sliding direction was detected in all tests after the compression step. In a few tests, a very small slope of $0.2-0.3^{\circ}$ was also present in the other direction. The width $w$ varied between the tows in the range 4 to $12 \mathrm{~mm}$, with an average of $7.74 \pm 1.65 \mathrm{~mm}$. The spreading of the tow was on average higher with epoxy, due to the internal lubrication between the fibres that favoured compression of the tow. The roughness of the tow also showed a high level of variation between samples. It was quantified as the average distance $d$ between the glass plane and the tow surface, as described in the previous section. The variability in the 
initial tow width, glass slope and roughness measured with the 3D microscope are presented in Figure 7 for all tows.

\subsection{Evolution of the friction coefficient in the first millimetres of sliding}

The reciprocal sliding tests revealed that in the first millimetres of sliding, the frictional behaviour was tow-dependent and that the friction coefficient can differ by as much as $40 \%$ between tows, in both dry and lubricated conditions. To understand the mechanisms behind this change in behaviour in the first millimetres of sliding, intermittent sliding tests were conducted under a 3D optical microscope. The shapes of the tows before and after each millimetre of sliding were examined and related to the friction. In these tests, the effect of the pre-tension of the tow on the frictional behaviour was also studied. Seven and six tows in the epoxy-lubricated condition and seven and four tows in the dry condition were tested under pre-tensions of $500 \mathrm{~g}(4.9 \mathrm{~N})$ and $100 \mathrm{~g}(0.98 \mathrm{~N})$ respectively for each case.

In these tests, the topography of the tow was measured over a period of around 10-20 minutes, the measurement time depending on the width of the tow. The friction force signal was recorded during sliding over $1 \mathrm{~mm}$ and a couple of minutes later. The procedure was repeated four times for a total sliding distance of $4 \mathrm{~mm}$. The four stages of force evolution shown in Figure 6(a) were repeated twice for each sliding increment, since moving the glass plate by $1 \mathrm{~mm}$ required two manual turns of the micrometric screw. A short recovery was observed in the middle of each sliding increment.

The average friction coefficients were first calculated in each sliding period corresponding to stage 3 in Figure 6(a). The results are presented in Figure 8 alongside the average friction coefficients for the last 3 $\mathrm{mm}$ of sliding in the reciprocal sliding tests shown in Table 1. They are also superposed onto the evolution of the instantaneous friction coefficients over time, as depicted in Figure 5. It can be seen that despite the incremental nature of this test and the long pauses between successive sliding increments, the evolution of the average friction coefficient repeated that observed in the continuous sliding test for both conditions. That is to say, the friction increased in the first two millimetres in dry conditions before becoming constant, while it continued to increase linearly with sliding in the epoxy-lubricated condition throughout all four sliding steps. The value of the friction coefficient for the last increment of the dry tows was very close to that averaged over the last $3 \mathrm{~mm}$ of sliding in the reciprocal sliding tests. However, it was higher in the epoxy-lubricated test than in any of the forward passes of the reciprocal sliding test. This may be related to time-dependent effects due to the viscosity of the liquid epoxy. 
The values of the friction coefficients measured in all tests in the dry condition are consistent with the values measured by Mulvihill et al. [9] for the equivalent nominal pressures in a parallel configuration

(0.0 to 0.45 ). The friction coefficient measured during the first increment is close to that obtained between two parallel tows $(0.24$ to 0.28$)$, indicating that the internal friction prevailed in this step. From the second increment to the end of sliding, the friction coefficient was closer to that measured between the glass and the carbon tow in the parallel orientation.

No significant difference was observed between the average friction coefficients for the two levels of pre-tension. However, the dispersion between the results was higher for a pre-tension of $100 \mathrm{~g}$ with epoxy than for a pre-tension of $500 \mathrm{~g}$. This is consistent with a lower bending stiffness, and thus a potential for higher mobility. Conversely, in dry conditions, the error bar was slightly lower for the lower pre-tension, meaning that the potential for higher mobility of fibres has less impact on friction in dry conditions than under lubrication.

The four stages of sliding and the points F1 to F5 shown schematically in Figure 6(a) were identified in the force signals of all incremental tests, in order to investigate the differences in behaviour between dry and epoxy-lubricated conditions under two levels of pre-tension. The change in the force at each stage was quantified as the average and standard deviation between all the incremental tests in each condition for each millimetre of glass sliding. To evaluate the contribution of each mechanism to the total friction force, Figure $9(a-d)$ presents the ratio of the difference between the force values at the beginning $F_{i}$ and at the end of each stage $F_{i+1}$, where $i$ varies from 1 to 4 , to the applied normal force $F_{N}$ of $6.68 \mathrm{~N}$, as follows:

$$
\Delta \mu_{i}=\frac{F_{i+1}-F_{i}}{F_{N}}
$$

Figure 9 shows that the major part of the friction coefficient presented in Figure 8 is due to the shear and microslip at the interfaces (stage 2). The initial drop in the force induced by the release of internal stress, quantified as $\Delta \mu_{1}$ in Figure 9(a), is generally smaller in the dry condition and decreases with sliding distance. The fibres are rearranged in each step, and approach a stabilised state where each fibre finds a less energy-costly position with respect to sliding. This effect is less marked with epoxy lubrication, since the fibres have more freedom to move due to the lubrication. The return toward the initial state after each sliding step is more likely in lubricated conditions than in the dry tow. 
According to our analysis, the rapid raise in the force during the second stage of sliding, shown as $\Delta \mu_{2}$ in Figure $9(\mathrm{~b})$, is due to internal kinetic friction and external static friction, which result in shear of the tow

before the external interface can slip. It is interesting to note that the values of $\Delta \mu_{2}$ for the epoxylubricated and dry conditions are closer for the first two millimetres of sliding than afterwards. The balance between the internal and external friction changes with the sliding distance due to rearrangement of the fibres.

The contribution $\Delta \mu_{2}$ remains relatively stable during the successive sliding steps in the epoxy-lubricated condition, meaning that the shear behaviour is similar in each step. The stiffness of the tow is high, which is demonstrated by the decrease in the friction force in stages 3 and 4 (see Figure 9(c) and 9(d)). The lubrication erases the differences between internal and external friction thresholds, and favours the return of the fibres after the initial shear deformation of the tow. This force relaxation begins during the actual sliding (stage 3, Figure 9(c)) and continues after the glass plate has stopped (stage 4, Figure 9(d)). In the dry condition, the internal friction threshold rises due to the higher packing of the tow resulting from bending, which favours the slip at the external interface. The shear contribution $\Delta \mu_{2}$ decreases linearly with sliding distance. This is also the case for the external sliding contribution $\Delta \mu_{3}$ (see Figure 9(c)). After the initial rearrangements in first and second increments, the external interface remains stable and the frictional force does not vary during further sliding. This is despite some elastic recovery in stage 4 (see Figure $9(d)$ ). In the fourth millimetre of sliding of the glass plate, the increase in the shear force $\Delta \mu_{2}$ is comparable to the elastic force recovery after the previous sliding increment, $\Delta \mu_{1}+\Delta \mu_{4}$, while no change in force is observed during the actual sliding in this increment, i.e. $\Delta \mu_{3}=0$. The frictional behaviour of the tow is stabilised.

The recovery of the tow after the glass plate has stopped, shown in Figure 9(d), was evaluated over a period of 10-20 s after the end of sliding. The drop in the force is similar for the dry and epoxylubricated conditions, and does not change significantly with sliding distance. However, a change in the kinetics of this recovery was noticed in the tests with epoxy, no doubt due to the viscosity of the epoxy. The change in the force between the end of one sliding step and the start of the next was studied, and a generalised Maxwell model describing a viscoelastic liquid was used. A Prony series with two relaxation times was fitted to the evolution of the force over time based on data from just after the end of sliding and just before the next sliding step, using the following equation: 


$$
F(t)=C_{1} e^{-\frac{t}{\tau_{1}}}+C_{2} e^{-\frac{t}{\tau_{2}}}
$$

The first time constant $\tau_{1}$ describes the relaxation at short times, several seconds after the end of sliding, while the second $\tau_{2}$ describes the longer times over which topography measurements are made. Figure 10 (a) shows the evolution of the first relaxation time $\tau_{1}$ with sliding increments. It confirms that in the first few millimetres, the relaxation is slower with epoxy than in dry conditions. However, this difference disappears after $3 \mathrm{~mm}$ of sliding. The drop in force $C_{1}$ due to this short-time relaxation is similar for all conditions and all steps, and is between 0.1 and $0.2 \mathrm{~N}$ on average. The second relaxation time constant $\tau_{2}$ is very high in all tests $(1.8-6.8 \mathrm{~h})$ compared to that for the fitted data, which was around 30 minutes for all tests. This means that the tow behaves like a viscoelastic solid rather than a liquid and has a constant stiffness at the end of relaxation period.

This force relaxation can be associated with the movements between the fibres, which continue after the end of sliding due to the constantly changing equilibrium between the imposed shear and compression loads and the bending resistance of the clamped tow, which tend to bring it back to its initial position. These effects are also balanced by static friction limits at the two external interfaces and between the fibres themselves.

To compare the residual friction force between the four conditions tested here, the friction coefficient after 30 minutes of force relaxation is evaluated, and the time and force constants are obtained from the experimental data. Figure 10 (b) shows that the residual static friction increases linearly during the successive sliding steps for all four conditions. Comparing these coefficients with those measured during sliding (Figure 8 and Figure 5, respectively), we can see that the drop is around 0.05 for each of the three steps with epoxy lubrication and in dry conditions under 500g of pre-tension, but is only 0.02 for dry conditions under $100 \mathrm{~g}$ of pre-tension.

This section has highlighted the evolution of the friction force (and the instantaneous friction coefficient) with sliding distance for the four conditions studied here. In the next section, the measurements of the shape and absolute position of the tow, made in situ by the 3D optical microscope, will be presented and analysed with the aim of explaining the frictional behaviour. 


\subsection{Tow deformation and displacement after first millimetres of sliding}

The topography of each tow was measured before each new sliding increment. It is important to note

that this measurement was made after the end of sliding and the elastic recovery of the previous increment, meaning that the shape of the tow during sliding was very likely to have been different. However, since the recovery was not complete, the evolution of the topography of the tow before and after each increment allows us to hypothesise about the transformations that it underwent during sliding.

For each sliding increment, the evolution of the residual shear angle, residual transversal strain and residual displacement of the right-hand edge of the tow and the roughness parameter were calculated from the profile and examined. The Hencky transversal strain for each sliding increment $i$ is defined as follows:

$$
\varepsilon_{t r i}=\ln \frac{w_{i}}{w_{0}}
$$

The shear angle is evaluated from the incremental change in the surface slope

$$
\gamma_{i}=\alpha_{i}-\alpha_{0}
$$

The displacement of the right-hand edge of the tow $u_{r}$ is computed by combining the absolute coordinates of each window of measurement, the position of the 2D centroid in the top view of the tow in this window and the current width of the tow, assuming that the tow is rectangular in this plane.

As expected, due to the initial shape of the tows, the dispersion between the results is very significant, although it is possible to detect and discuss the overall tendencies of these results. First, we discuss the mechanisms of epoxy lubrication. Figure 11(a) shows that the shear angle after recovery is close to zero for all tests except two. The average tow shear angle after the third increment is $0.01 \pm 0.18^{\circ}$ at a pretension of $500 \mathrm{~g}$ and $0.01 \pm 0.16^{\circ}$ at a pre-tension of $100 \mathrm{~g}$. All tows except one contract with sliding, as shown in Figure 11(b). The tow that does not deform in sliding is one of the two that have a high negative shear, similar to the dry condition. The contraction is particularly noticeable for the tows under a pre-tension of $100 \mathrm{~g}$. In this case, the transversal strain reaches $-13.2 \pm 2.14 \%$ on average after $3 \mathrm{~mm}$ of sliding; for comparison, the transversal strain under a pre-tension of $500 \mathrm{~g}$ is only $-6.5 \pm 4.4 \%$. The residual displacement of the tows is rather sporadic, with some movements to the right and some to the 
left after sliding, but is generally positive in the orientation of sliding of the glass. The tow displacement after the third increment reaches $0.48 \pm 0.26 \mathrm{~mm}$ at a pre-tension of $500 \mathrm{~g}$ and $0.48 \pm 0.47 \mathrm{~mm}$ at $100 \mathrm{~g}$.

In contrast, dry sliding implies a linear decrease in the shear angle, meaning that the tow becomes increasingly flat with sliding and the initial slope tends to disappear. The shear angle after $3 \mathrm{~mm}$ of sliding is $-0.33 \pm 0.18^{\circ}$ at a pre-tension of $500 \mathrm{~g}$ and $-0.35 \pm 0.20^{\circ}$ at $100 \mathrm{~g}$. These values show that there is no effect of pre-tension on the shear angle. The slope does not disappear completely after four sliding increments, and is equal to $0.47 \pm 0.39^{\circ}$ and $0.43 \pm 0.32^{\circ}$ at pre-tensions of $100 \mathrm{~g}$ and $500 \mathrm{~g}$, respectively. However, the transversal strain in the dry condition shows that half of the tows contract after sliding and half expand. The average strain is $1.4 \pm 2.9 \%$ for a pre-tension of $500 \mathrm{~g}$ and $-0.3 \pm 7.7 \%$ for $100 \mathrm{~g}$. These deformations are associated with positive and progressive displacement of the tow in the direction of the glass sliding. The displacement after the third increment is $0.91 \pm 0.22 \mathrm{~mm}$ at $500 \mathrm{~g}$ pre-tension and $1.07 \pm 0.33 \mathrm{~mm}$ at $100 \mathrm{~g}$.

The results presented in Figure 11(a-c) seem to indicate that the tows under lubrication tend to slide back to the initial place and to regain the initial slope of the upper surface after the increments, while becoming more and more compact in the transversal direction. This recovery of shape and displacement is more limited in the dry condition. Given the higher friction threshold at the external interfaces than between the fibres, it is likely that the force relaxation measured after the tests relates to the internal deformation of the tow rather than the displacement with respect to the two interfaces. This is confirmed by the residual displacement of the tow presented in Figure 11(c), which increases after each increment. Moreover, the displacement of the tow after the first millimetre of sliding of the glass plate is twice as high as in the next two steps. This means that during at least half of this step, the tow is stuck to the sliding glass plate and slides only on the lower plate.

As shown in Figure 7, the tows were not all perfectly smooth before the tests but had rather significant roughness. Figure 11(d) shows that for three of the four conditions, the average distance between the glass and the surface of the tow decreases from the initial state after the first sliding increment and then stays constant with sliding. However, the tows tested with epoxy an a pre-tension of $500 \mathrm{~g}$ do not change their surface state with sliding on average until after the second sliding increment. The error bars, which represent \pm one standard deviation, tend to decrease with sliding for all four conditions, meaning that the initial state of the surface has a limited impact after sliding and that all the tows tend 
towards the same surface state. The average distance between the glass plate and the tow surface is around $10 \pm 2 \mu \mathrm{m}$ after $3 \mathrm{~mm}$ of sliding. This is comparable to the diameter of a carbon fibre, which is

\section{$6.7 \mu \mathrm{m}$ on average.}

\section{Conclusions}

Experiments involving reciprocating and incremental sliding friction between a carbon fibre tow and a glass plate were conducted in two conditions: dry and lubricated by liquid epoxy. The friction force was continuously measured during the tests and the topography of the carbon tows was measured with a 3D microscope. The three objectives of this work were to identify the mechanisms controlling the friction of carbon fibre tow in transversal orientation, analyse the effect of the sliding distance on the frictional response of the tow and study the effect of the lubrication provided by the resin. Our conclusions on these three points are summarized hereafter.

The friction results in both the dry and lubricated conditions were initially tow-dependent, but the difference between tows tended to disappear with sliding distance. The stabilised friction coefficients in the dry condition were estimated as $0.33 \pm 0.036$ and $0.29 \pm 0.033$ for forward and backward sliding, respectively, while in the epoxy-lubricated condition, they were equal to $0.20 \pm 0.020$ and $0.26 \pm 0.014$. Several mechanisms, including the shear resistance of the micro-junctions within the tow and at the interface with the glass, and a change in the contact area due to deformation of the tow, contribute to the friction during both the dry and lubricated friction tests. Based on the relative evolution of friction force, four stages of friction were identified: internal stress relaxation, shear deformation of the tow and microslips at the interfaces, macroslip of the external interfaces, and force relaxation after the end of sliding of the glass.

The friction experiments with dry tows revealed that the average friction coefficient increased during the first few millimetres of sliding before stabilising at a constant value. The lower friction coefficient in the first millimetre of sliding was associated with the internal friction between carbon fibres, while the tow surface was stuck to the glass plate. The stabilised friction is due to macroslipping at the glass-tow interface, and is accompanied by flattening and smoothing of the surface of the tow in contact with the glass.

When the tows are lubricated with liquid epoxy, the friction force increases linearly with sliding distance without actually stabilising in the range tested in the incremental experiments. This is certainly due to 
the time dependence induced by the high viscosity of the epoxy lubricant coupled with intermittent

nature of testing. All of the lubricated tows demonstrated residual contraction after recovery that

increased with sliding distance.

In order to have a better understanding of the mechanisms controlling the friction of carbon fibre tows,

an accurate control of the sliding motion by using an electrical motor as well as in-situ observations

during sliding are planned. These future experiments will allow quantifying the different physical

phenomena to finally propose a physically founded friction model for carbon fibre tows.

\section{Acknowledgements}

The authors are very grateful to Prof. Michael Sutcliffe from the University of Cambridge, for useful discussions throughout this work and for supplying the carbon tows. This work was partially funded by the Institut Pprime ACl programme and pertains to the French government program "Investissements d'Avenir" (LABEX INTERACTIFS, reference ANR-11-LABX-0017-01 and EUR INTREE, reference ANR-18-

EURE-0010). Pprime Institute gratefully acknowledges "Contrat de Plan Etat - Région Nouvelle-

Aquitaine" (CPER) as well as the "Fonds Européen de Développement Régional (FEDER)" for their

financial support to the reported work.

References

1. Roselman IC, Tabor D. The friction of carbon fibres. J Phys D Appl Phys 1976;9(17):2517.

2. Tourlonias M, Bueno M-A, Poquillon D. Friction of carbon tows and fine single fibres. Compos A Appl Sci Manuf 2017;98:116-123.

3. Tourlonias $M$, Bueno $M-A$, Jordan $C$, Poquillon $D$. Influence of wear on the sizing layer and desizing of single carbon fibre-to-fibre friction. Wear 2018;402-403:64-70. ISSN 0043-1648.

4. Sugimoto $Y$, Shimamoto $D$, Hotta $Y$. Evaluation of kinetic friction coefficients between single carbon fibers. Carbon 2020;167:264-269.

5. Cornelissen B, de Rooij MB, Rietman B, Akkerman R. Frictional behaviour of high performance fibrous tows: A contact mechanics model of tow-metal friction. Wear 2013;305(1-2):78-88.

6. Cornelissen B, Rietman B, Akkerman R. Frictional behaviour of high performance fibrous tows: Friction experiments. Compos A Appl Sci Manuf 2013;44:95-104.

7. Smerdova O, Sutcliffe MPF. Novel experimental method for microscale contact analysis in composite fabric forming. Exp Mech 2015;55(8):1475-83.

8. Smerdova O, Sutcliffe MPF. Multiscale tool-fabric contact observation and analysis for composite fabric forming. Compos A Appl Sci Manuf 2015;73:116-24.

9. Mulvihill DM, Smerdova O, Sutcliffe MPF. Friction of carbon fibre tows. Composites 2017; 93:185-198.

10. Mulvihill DM, Sutcliffe MPF. Effect of tool surface topography on friction with carbon fibre tows for composite fabric forming. Compos A Appl Sci Manuf 2017;93:199-206.

11. Cornelissen B, de Rooij MB, Rietman B, Akkerman R. Frictional behavior of carbon fiber tows: A contact mechanics model of tow-tow friction. Text Res J 2014;84(14):1476-88.

12. Chakladar ND, Mandal P, Potluri P. Effects of inter-tow angle and tow size on carbon fibre friction. Compos A Appl Sci Manuf 2014;65:115-24

13. Tourlonias M, Bueno M-A, Fassi G, Aktas I, Wielhorski Y. Influence of friction angle between carbon single fibres and tows: Experimental analysis and analytical model. Compos 2019;124:105478.

14. Dackweiler M, Hagemann L, Coutandin S, Fleischer J. Experimental investigation of frictional behavior in a filament winding process for joining fiber-reinforced profiles. Compos Struct 2019;229:111436.

15. Ten Thije RHW, Akkerman R, Ubbink M, van der Meer L. A lubrication approach to friction in thermoplastic composites forming processes. Compos A Appl Sci Manuf 2011;42:950-960. 
16. Fetfatsidis KA, Jauffrès D, Sherwood JA, Chen J. Characterization of the tool/fabric and fabric/fabric friction for woven-fabric composites during the thermostamping process. Int J Mater Form 2013;6:209221. DOI 10.1007/s12289-011-1072-5

17. Lin $\mathrm{H}$, Harrison $\mathrm{P}$, van de Haar $\mathrm{K}$, Long AC, Akkerman R, Clifford MJ. Investigation of tool-ply friction of viscous textile composites. In: Proc TEXCOMP-8, 2006.

18. Murtagh AM, Monaghan MR, Mallon PJ. Investigation of the interply slip process in continuous fibre thermoplastic composites. In: Proc 9th ICCM Conf, 1993.

19. Gorczyca-Cole JL, Sherwood JA, Chen J. A friction model for thermostamping commingled glasspolypropylene woven fabrics. Compos A Appl Sci Manuf 2007;38:393-406.

20. Sach $U$ et al. Characterization of the dynamic friction of woven fabrics: Experimental methods and benchmark results. Compos A Appl Sci Manuf 2014;67:289-298.

21. Sakkalatty Dharmalingam A, Hemmer J, Lectez A-S, Binetruy C, Comas-Cardona S. Evolution of single carbon and glass fibrous tow cross-sections in dry and lubricated states during compaction perpendicular to the fibers. Compos B Eng 2018;148:235-242.

22. Latil P, Orgéas L, Geindreau C, Dumont PJJ, Rolland du Roscoat S. Towards the 3D in situ characterisation of deformation micro-mechanisms within a compressed bundle of fibres. Compos Sci Technol 2011;71:480-488. 
Figure 1 : A simplified drawing of the experimental device.

Figure 2. (a) Experimental set-up and(b) the tow fixed on the glass plate

Figure 3 Evolution of the surface topography of the tow after sliding with epoxy lubrication and $100 \mathrm{~g}$ of pre-tension

Figure 4 Example of the mean profile of a tow and the detected glass surface

Figure 5. Evolution of the instantaneous friction coefficient during the first forward sliding pass of reciprocal sliding tests in (a) dry conditions and (b) epoxy-lubricated conditions. The average and standard deviation of several tows for each $1 \mathrm{~mm}$ sliding of the incremental tests is indicated by triangles.

Figure 6 (a) Schematic of the evolution of the measured force signal with time during one turn of the micrometric screw; (b) free body diagram of the cross-section of the tow

Figure 7. Initial shapes of the tows with pre-tension $100 \mathrm{~g}$ and $500 \mathrm{~g}$ in dry and epoxy-lubricated conditions, as measured under the microscope

Figure 8. Mean friction coefficients for several tows for each $1 \mathrm{~mm}$ step of the incremental test, and for each pass of the reciprocal sliding tests averaged over the last $3 \mathrm{~mm}$

Figure 9. Relative change in the measured friction coefficient in each of the four stages of incremental sliding

Figure 10. (a) Evolution of the first time constant with sliding and (b) residual static friction coefficient after $30 \mathrm{~min}$ of relaxation after each of three $1 \mathrm{~mm}$ increments of sliding

Figure 11. (a) Residual shear angle, (b) residual transversal strain, (c) residual displacement and (d) roughness parameter, calculated from the measurements of the tow surface in incremental tests 


\begin{tabular}{|l|l|l|l|l|}
\hline & \multicolumn{2}{|l|}{ Dry } & \multicolumn{2}{l|}{ Epoxy-lubricated } \\
& Forward & Backward & Forward & Backward \\
\hline Pass 1 & & & \\
\hline Pass 2 & $0.34 \pm 0.051$ & $0.31 \pm 0.043$ & $0.19 \pm 0.026$ & $0.25 \pm 0.014$ \\
\hline Pass 3 & $0.35 \pm 0.039$ & $0.30 \pm 0.043$ & $0.21 \pm 0.029$ & $0.26 \pm 0.007$ \\
\hline Pass 4 & $0.35 \pm 0.044$ & $0.29 \pm 0.040$ & $0.20 \pm 0.012$ & $0.27 \pm 0.010$ \\
\hline Average of all cycles & $0.33 \pm 0.036$ & $0.29 \pm 0.033$ & $0.20 \pm 0.020$ & $0.26 \pm 0.014$ \\
\hline
\end{tabular}

Table 1. Average kinetic friction coefficients of the last $3 \mathrm{~mm}$ of sliding and their standard deviations for dry and epoxy-lubricated reciprocal sliding tests. 


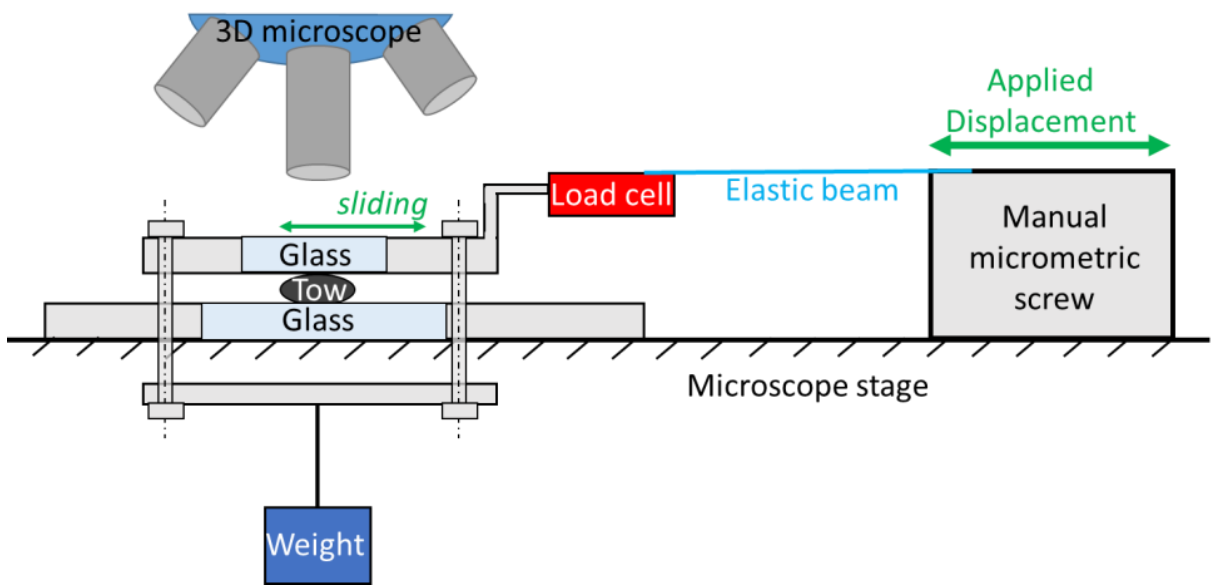

Figure 1 : A simplified drawing of the experimental device.

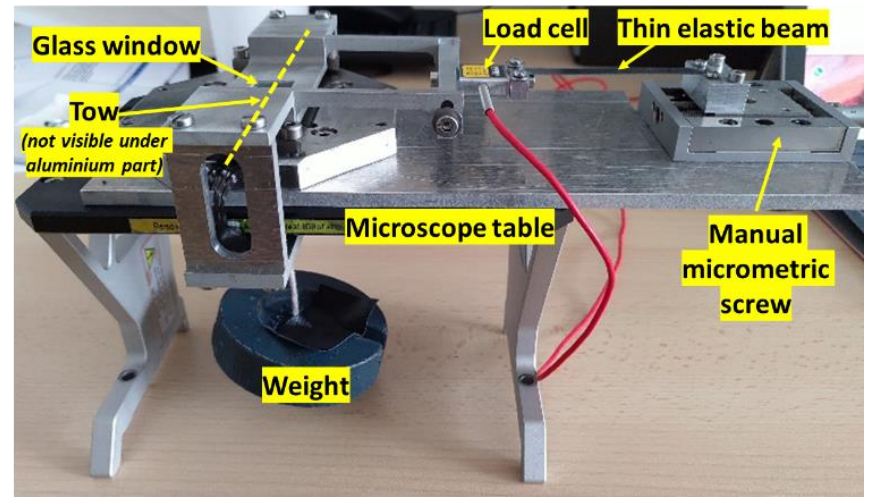

(a)

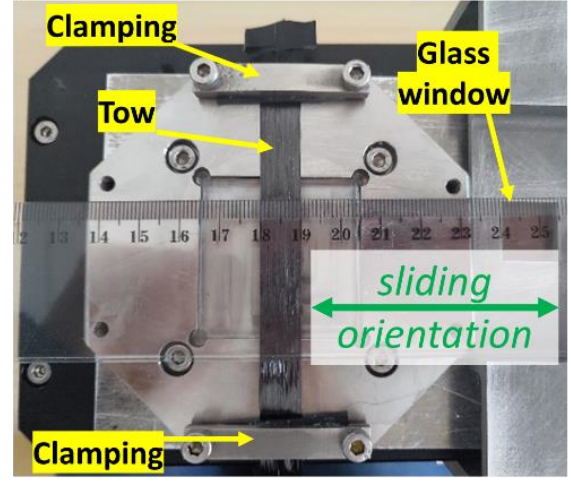

(b)

Figure 2. (a) Experimental set-up and (b) the tow fixed on the glass plate

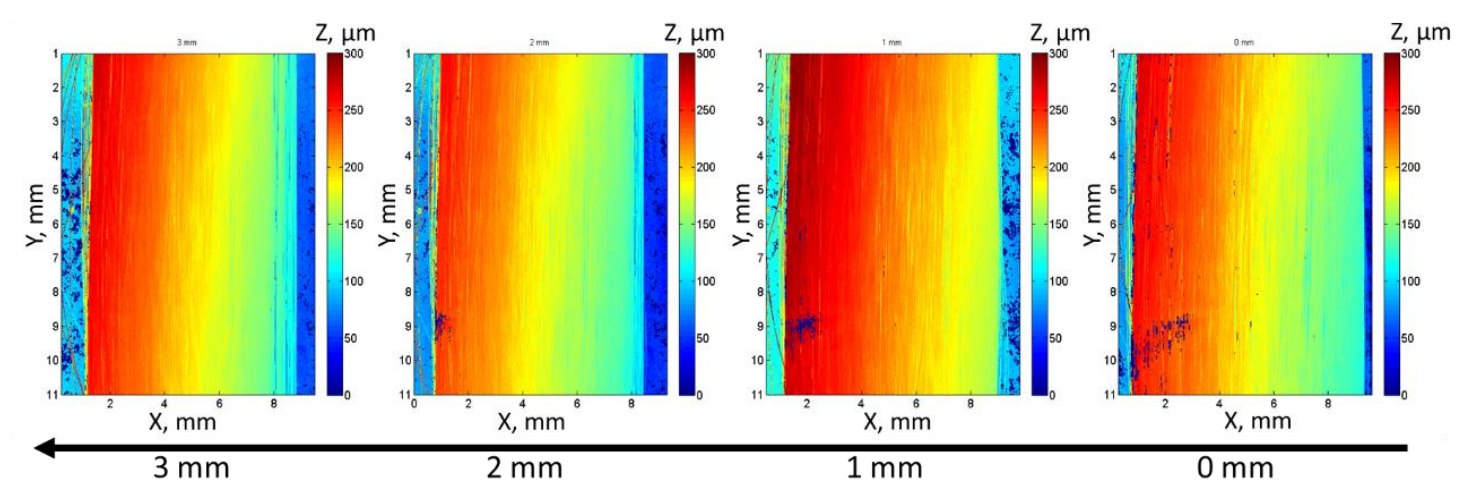

Glass sliding distance

Figure 3 Evolution of the surface topography of the tow after sliding with epoxy lubrication and $100 \mathrm{~g}$ of pre-tension 


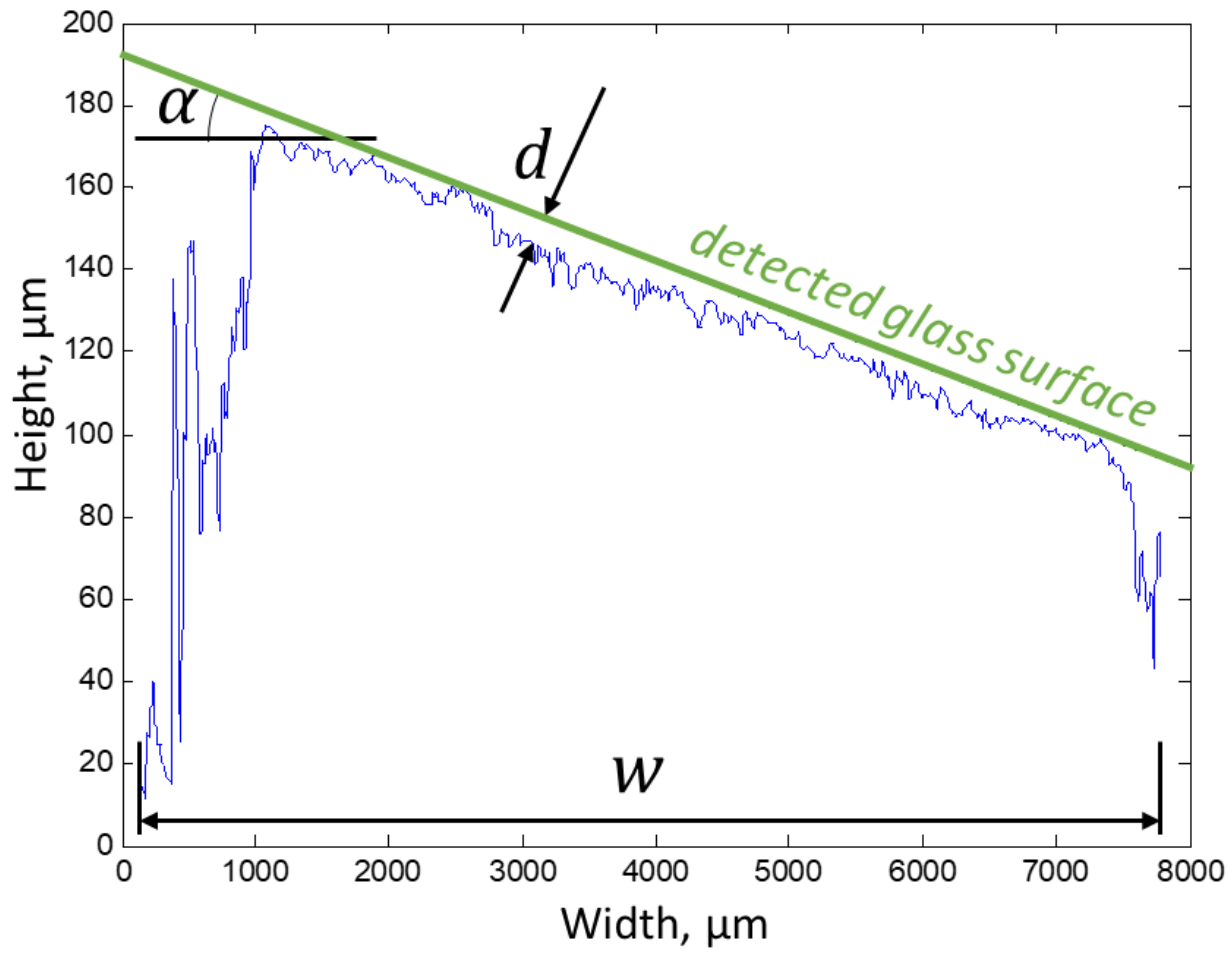

Figure 4 Example of the mean profile of a tow and the detected glass surface 

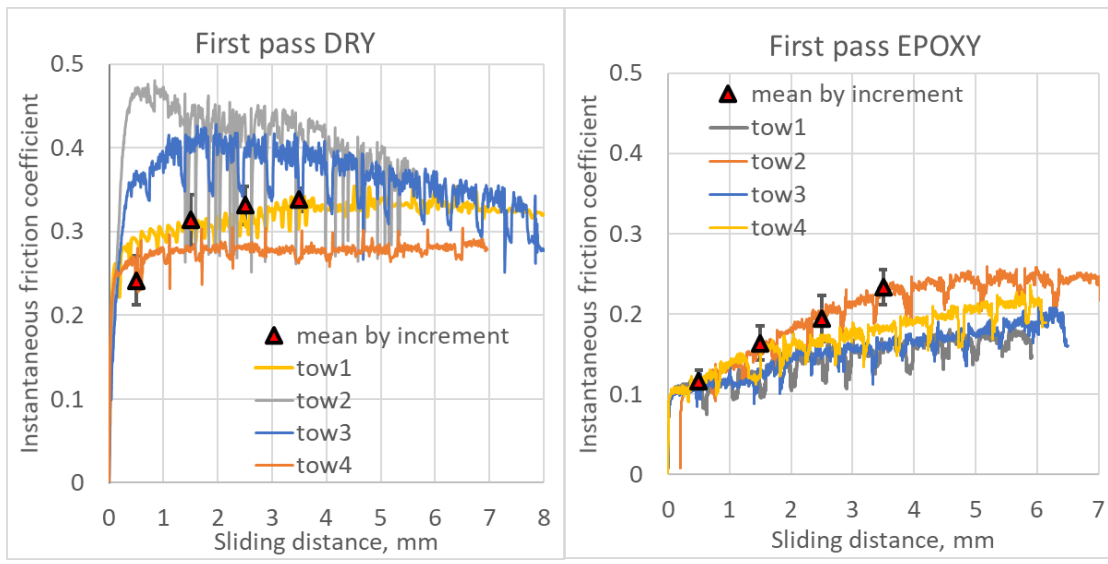

(a)

(b)

Figure 5. Evolution of the instantaneous friction coefficient during the first forward sliding pass of reciprocal sliding tests in (a) dry conditions and (b) epoxy-lubricated conditions. The average and standard deviation of several tows for each $1 \mathrm{~mm}$ sliding of the incremental tests is indicated by triangles.

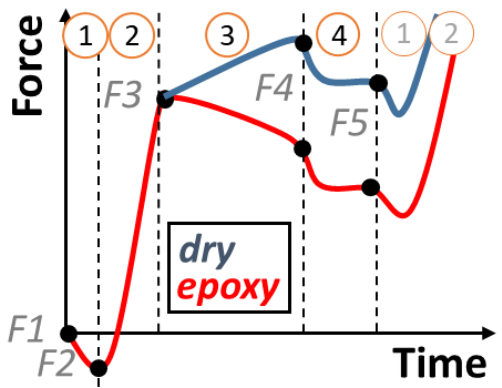

1 - internal stress relaxation

2 - internal shear

3 - sliding friction

4 - (visco)elastic recovery

(a)

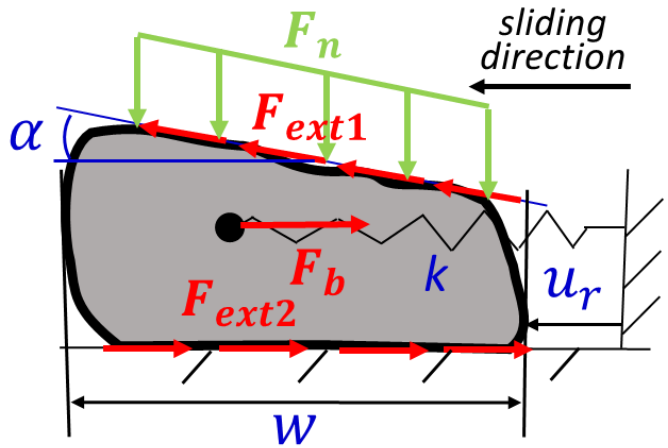

(b)

Figure 6 (a) Schematic of the evolution of the measured force signal with time during one turn of the micrometric screw; (b) free body diagram of the cross-section of the tow 

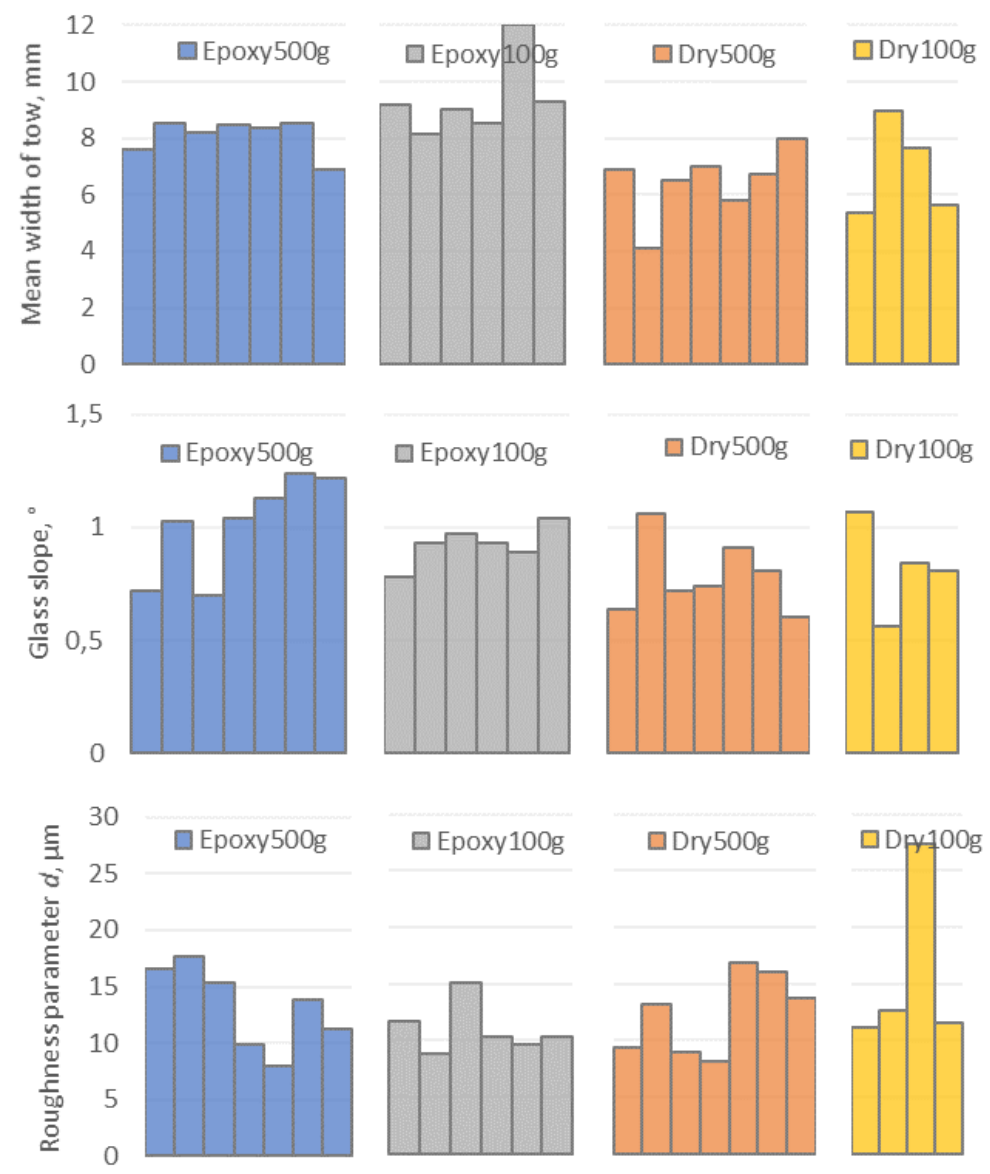

Figure 7. Initial shapes of the tows with pre-tension $100 \mathrm{~g}$ and $500 \mathrm{~g}$ in dry and epoxy-lubricated conditions, as measured under the microscope

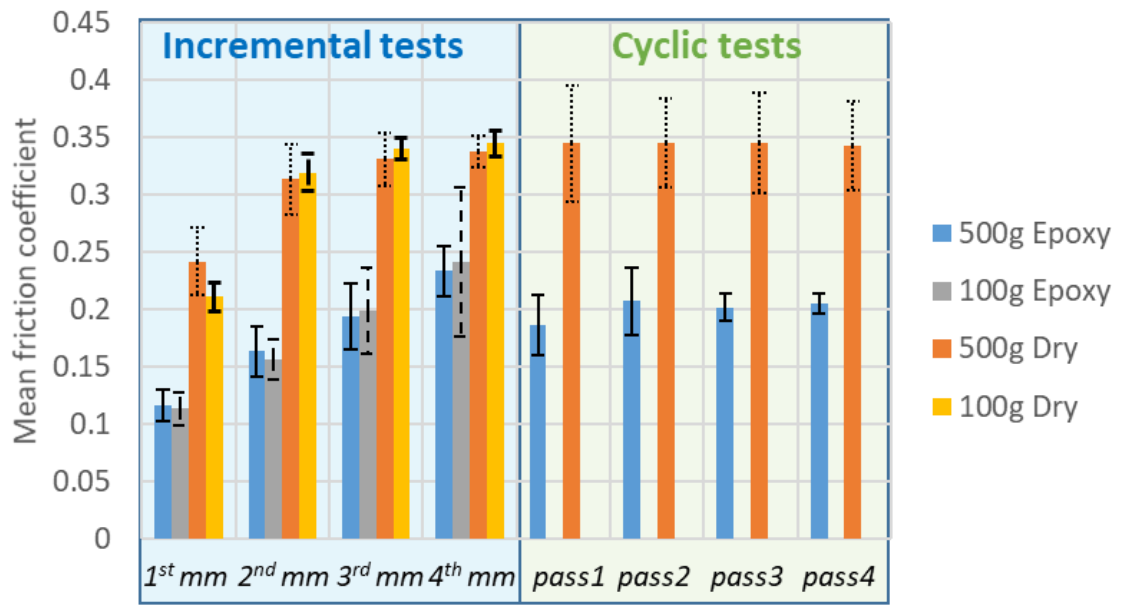

Figure 8. Mean friction coefficients for several tows for each $1 \mathrm{~mm}$ step of the incremental test, and for each pass of the reciprocal sliding tests averaged over the last $3 \mathrm{~mm}$ 

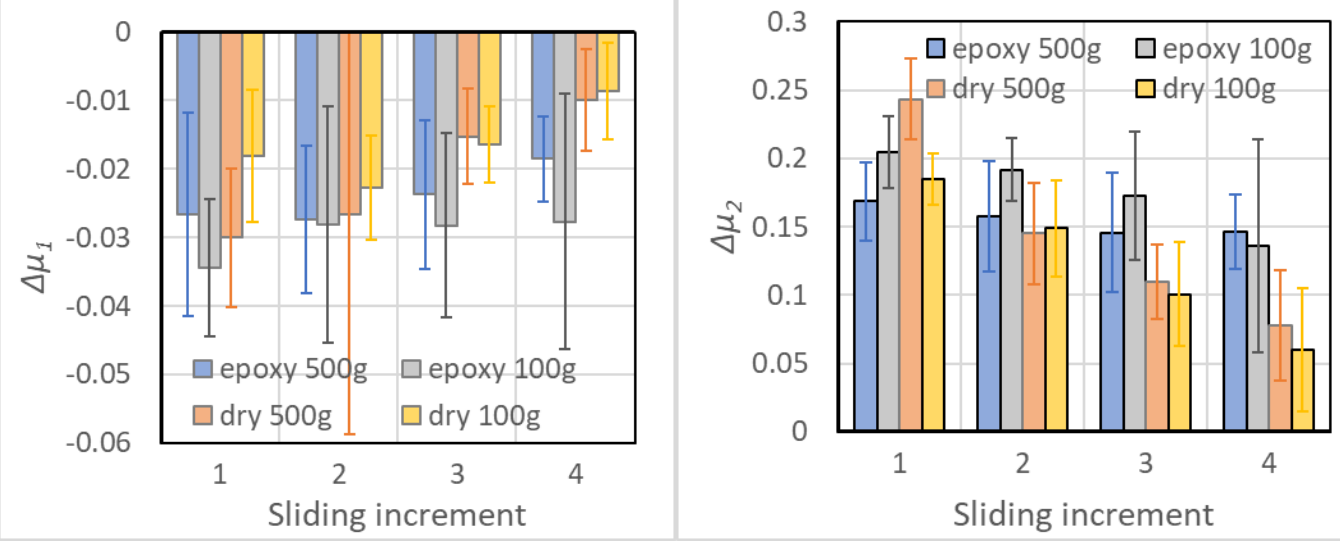

(a)

(b)
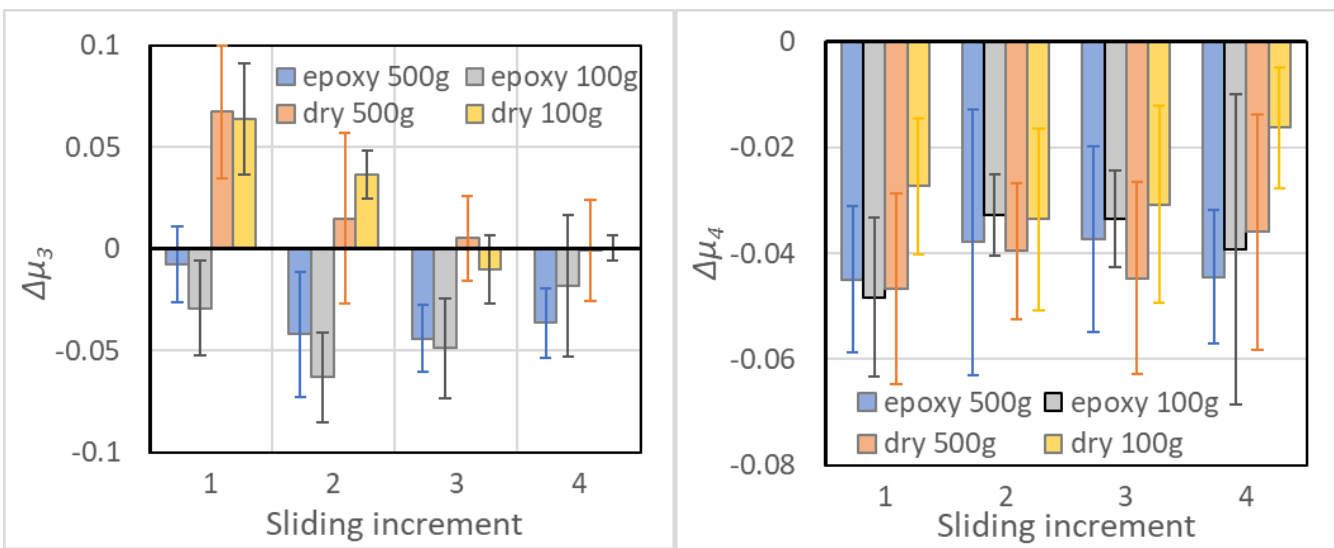

(c)

(d)

Figure 9. Relative change in the measured friction coefficient in each of the four stages of incremental sliding

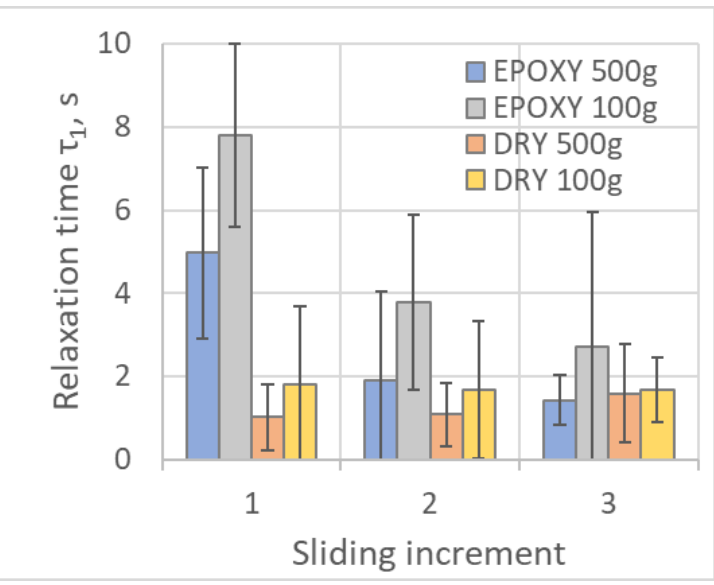

(a)

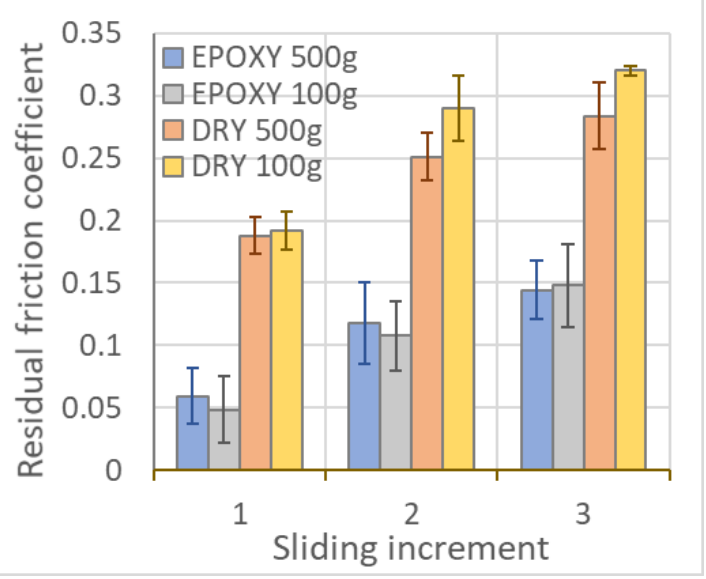

(b)

Figure 10. (a) Evolution of the first time constant with sliding and (b) residual static friction coefficient after 30 min of relaxation after each of three $1 \mathrm{~mm}$ increments of sliding 

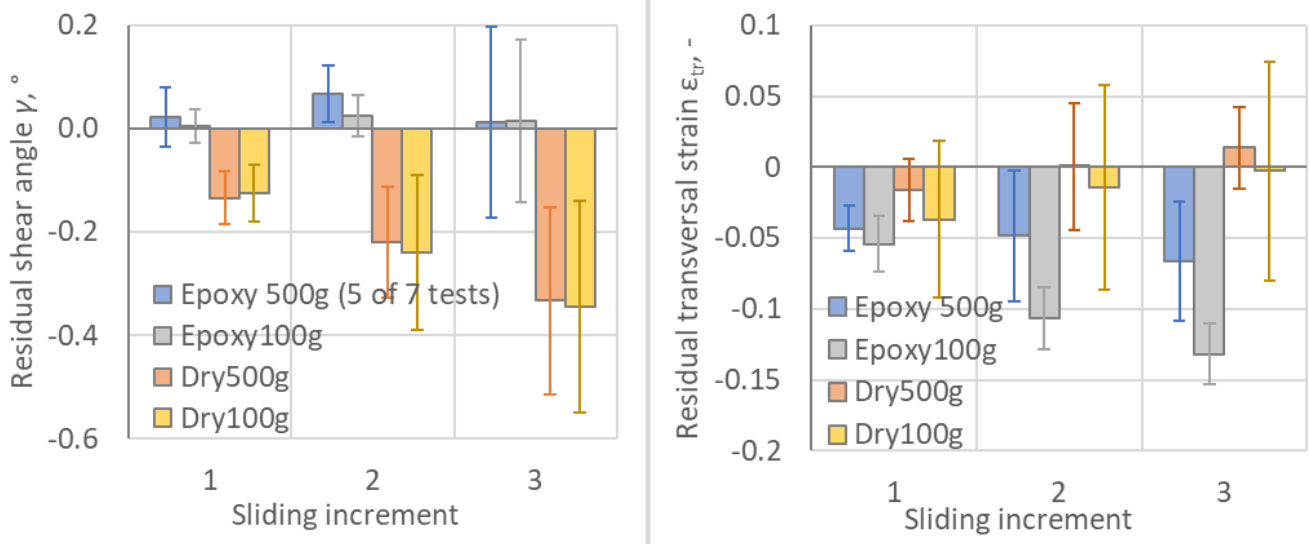

(a)

(b)
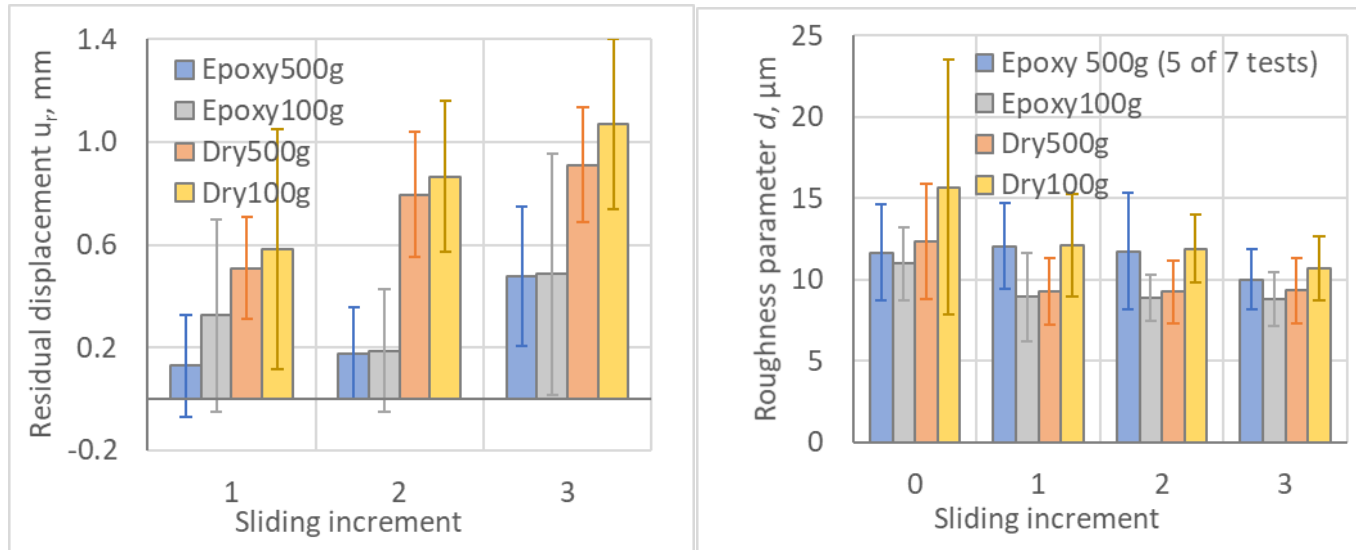

(c)

(d)

Figure 11. (a) Residual shear angle, (b) residual transversal strain, (c) residual displacement and (d) roughness parameter, calculated from the measurements of the tow surface in incremental tests 


\section{Fig 1}

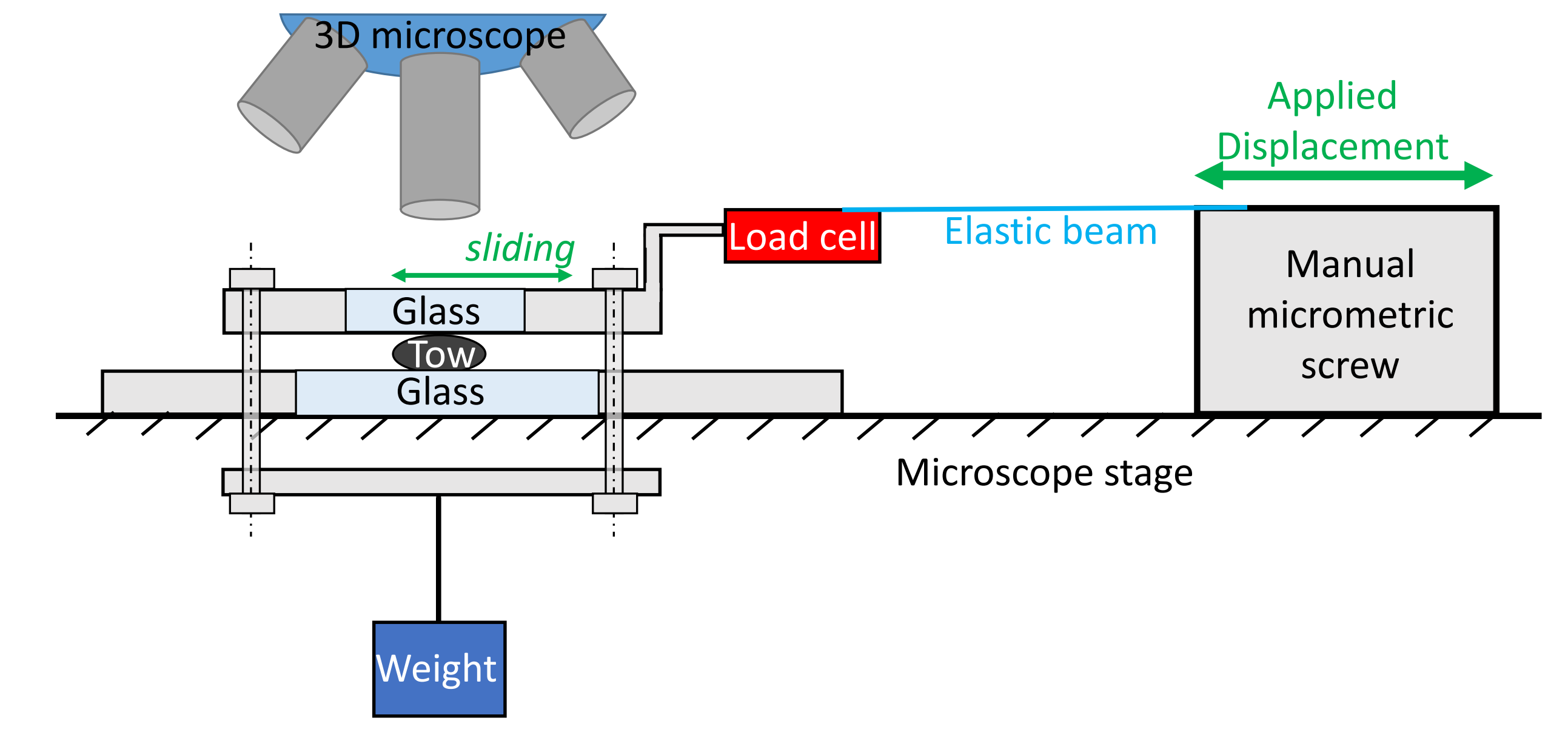


Fig $2 a$

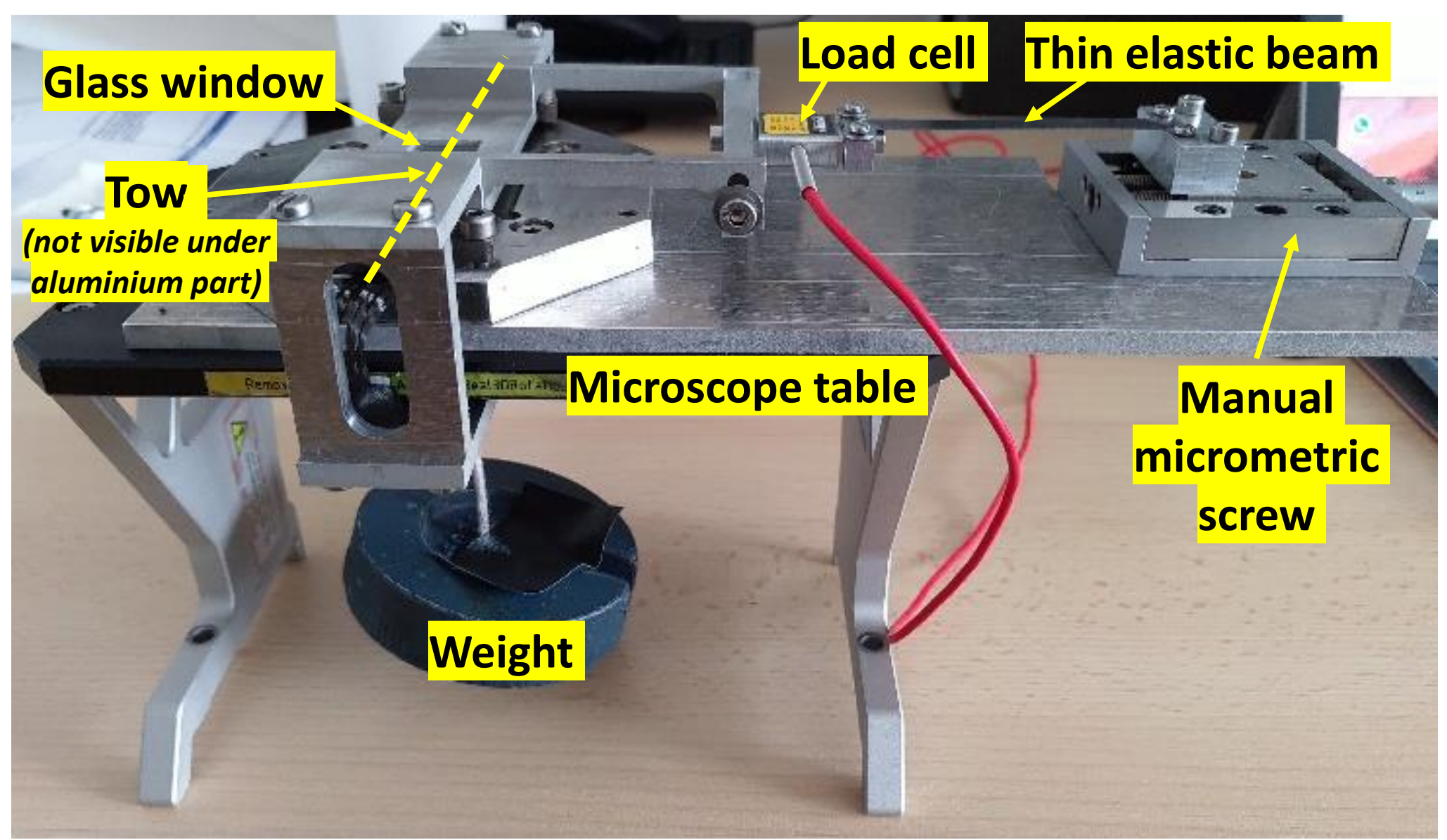


Fig $2 b$

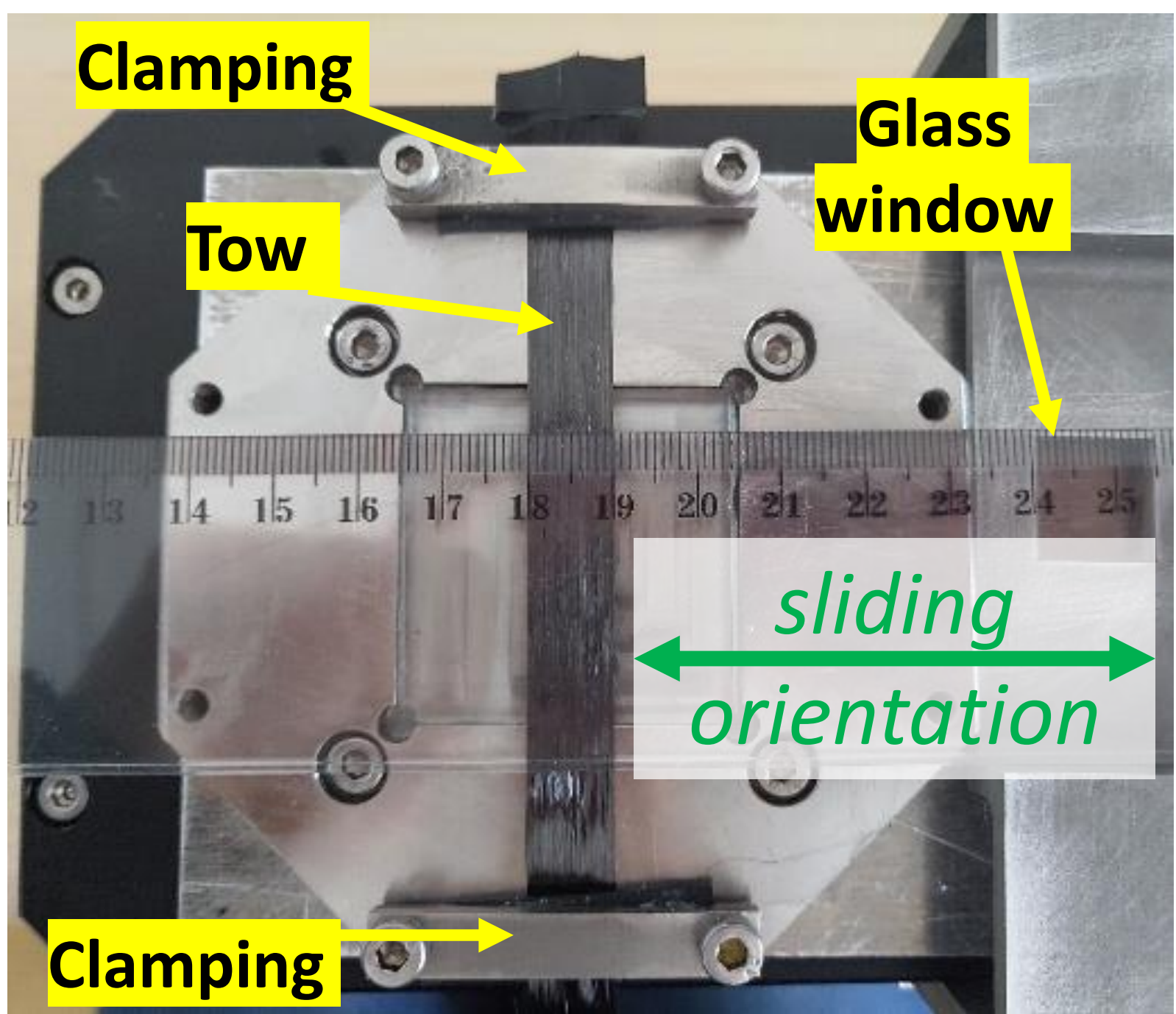


Fig 3

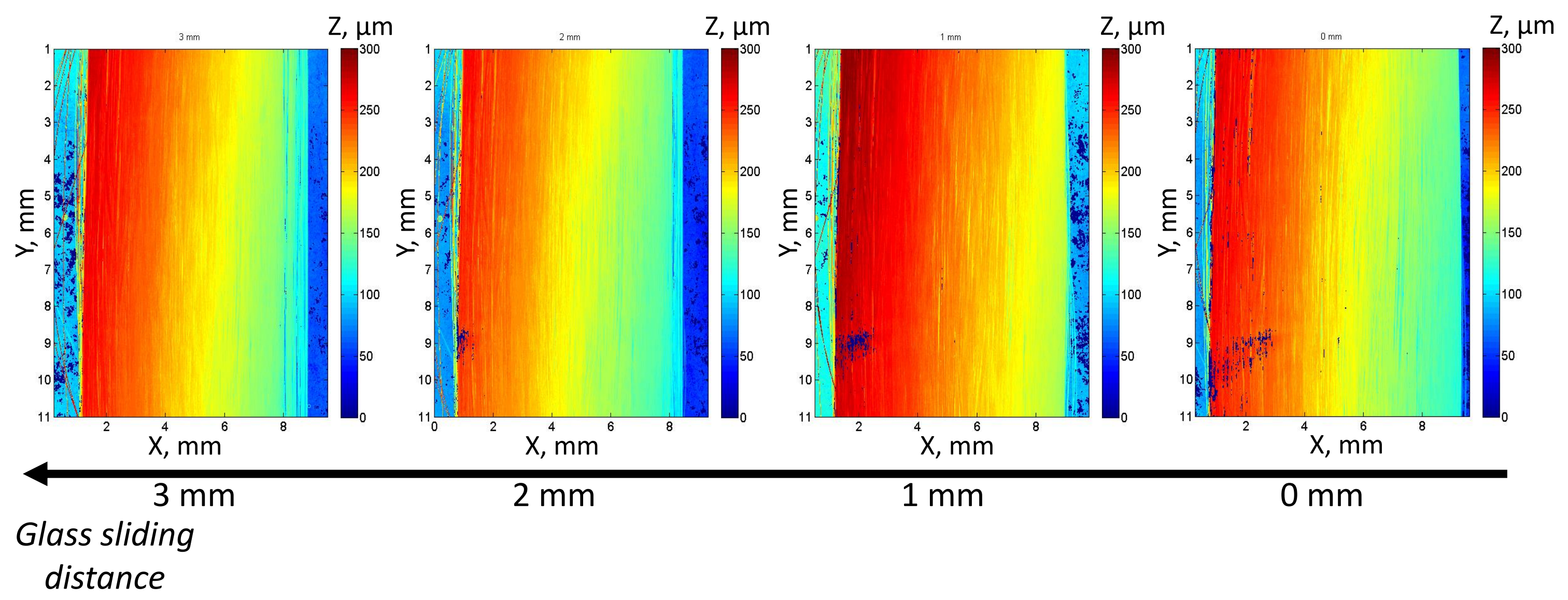


Fig 4

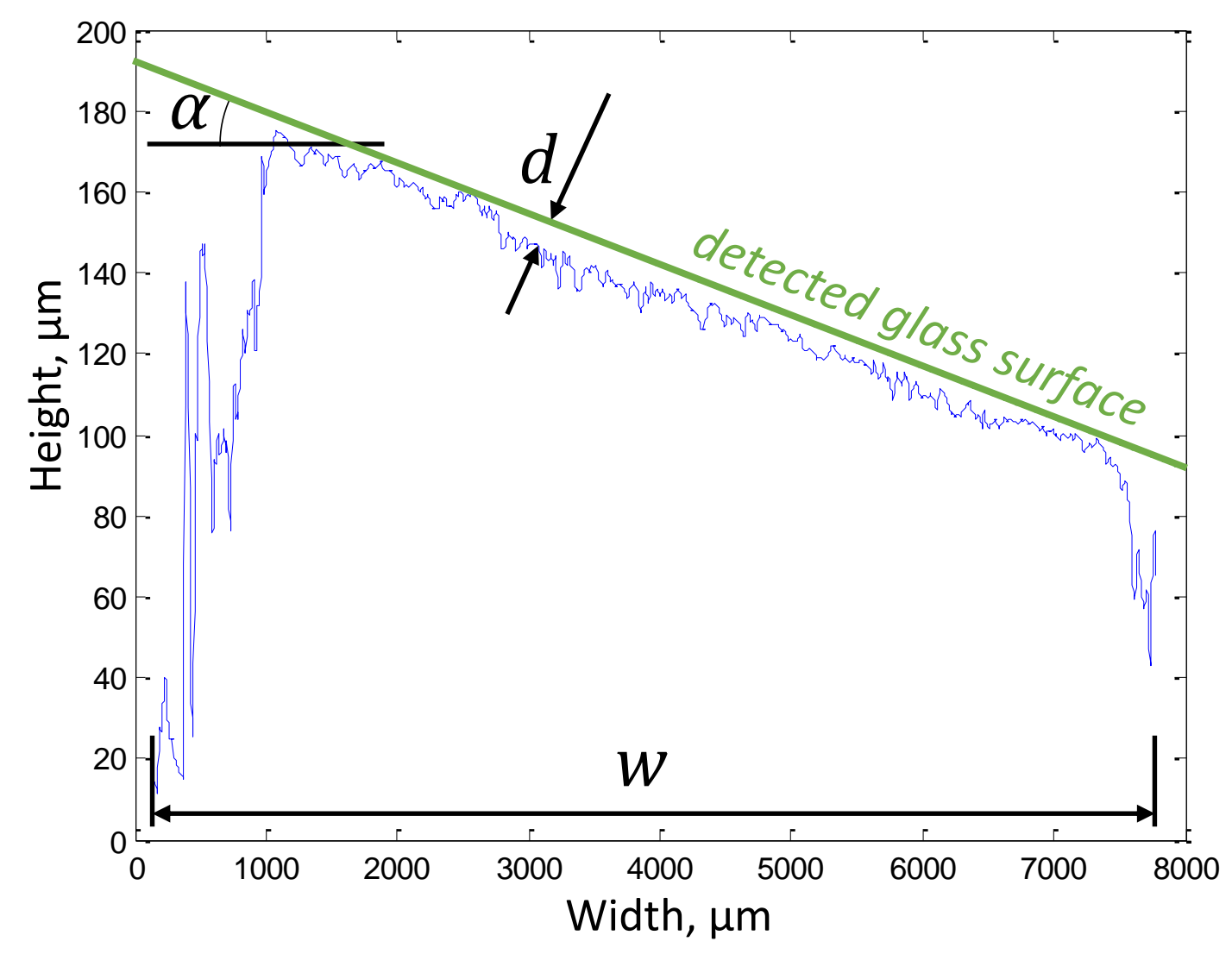




\section{Figs $5 a, b$}
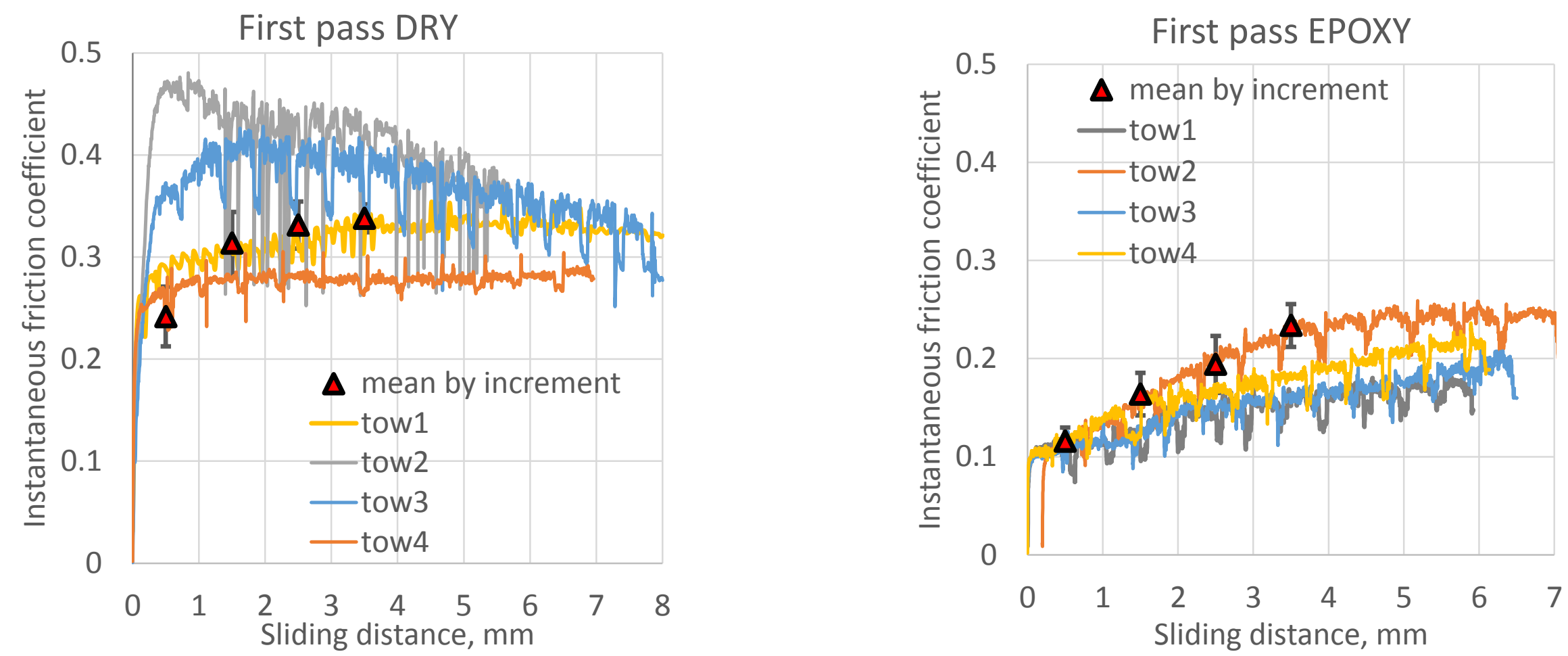


\section{Fig 6a, b}

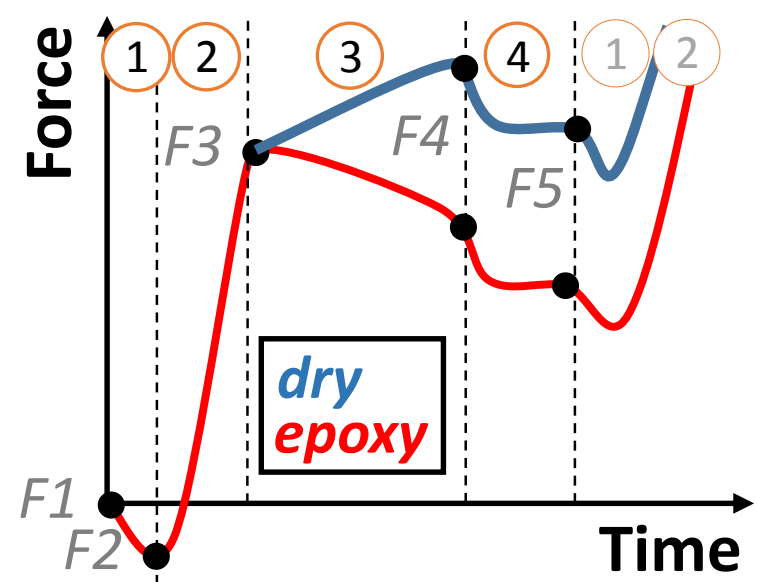

1 - internal stress relaxation

2 - internal shear

3 - sliding friction

4 - (visco)elastic recovery

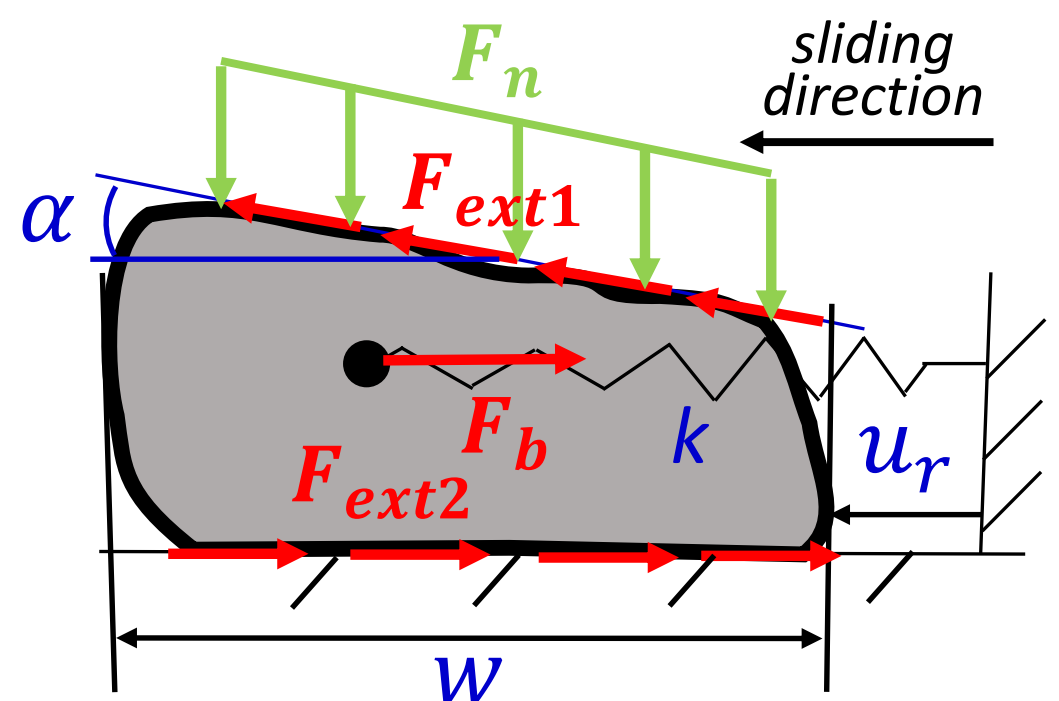


Fig 7

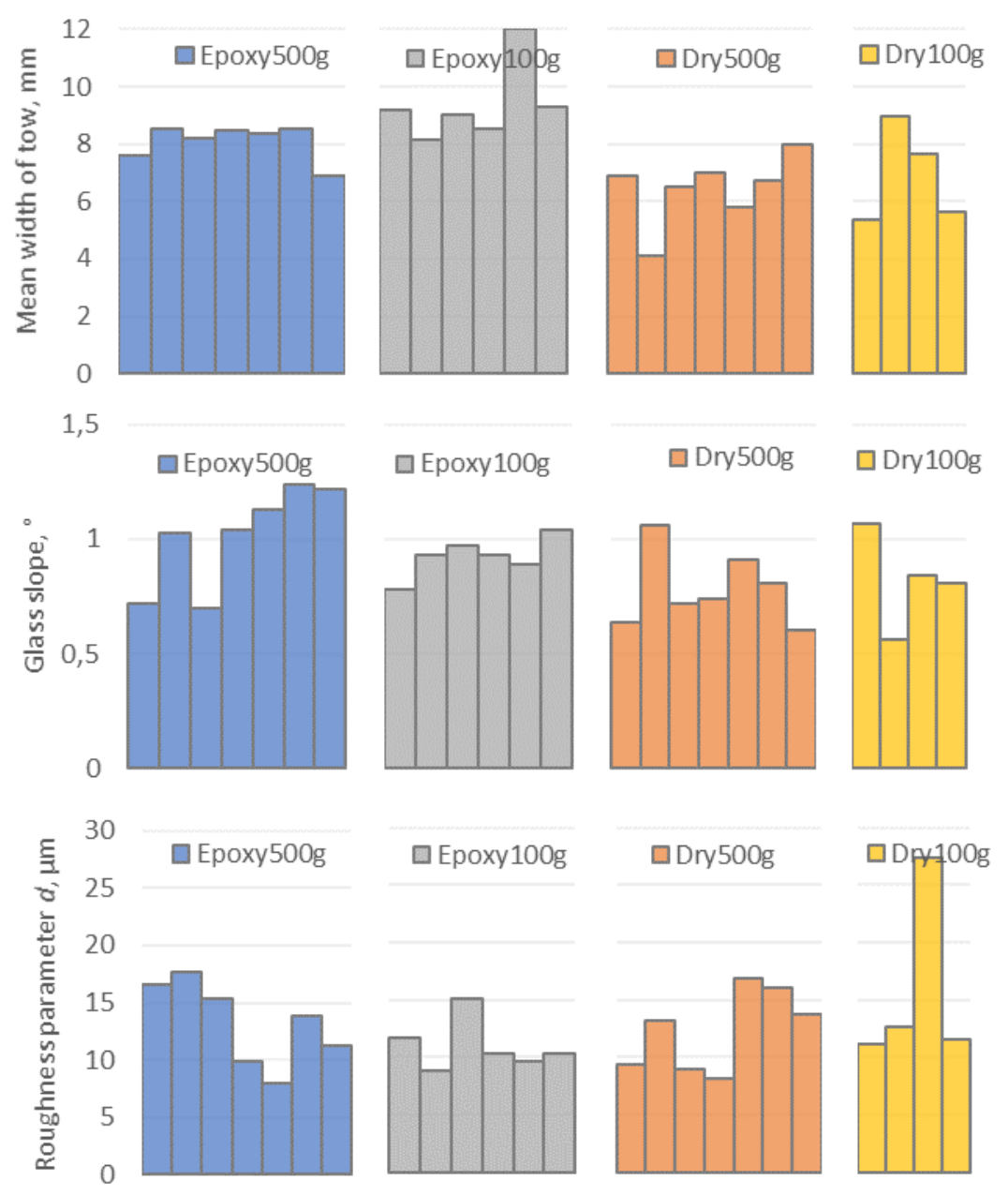


Fig 8

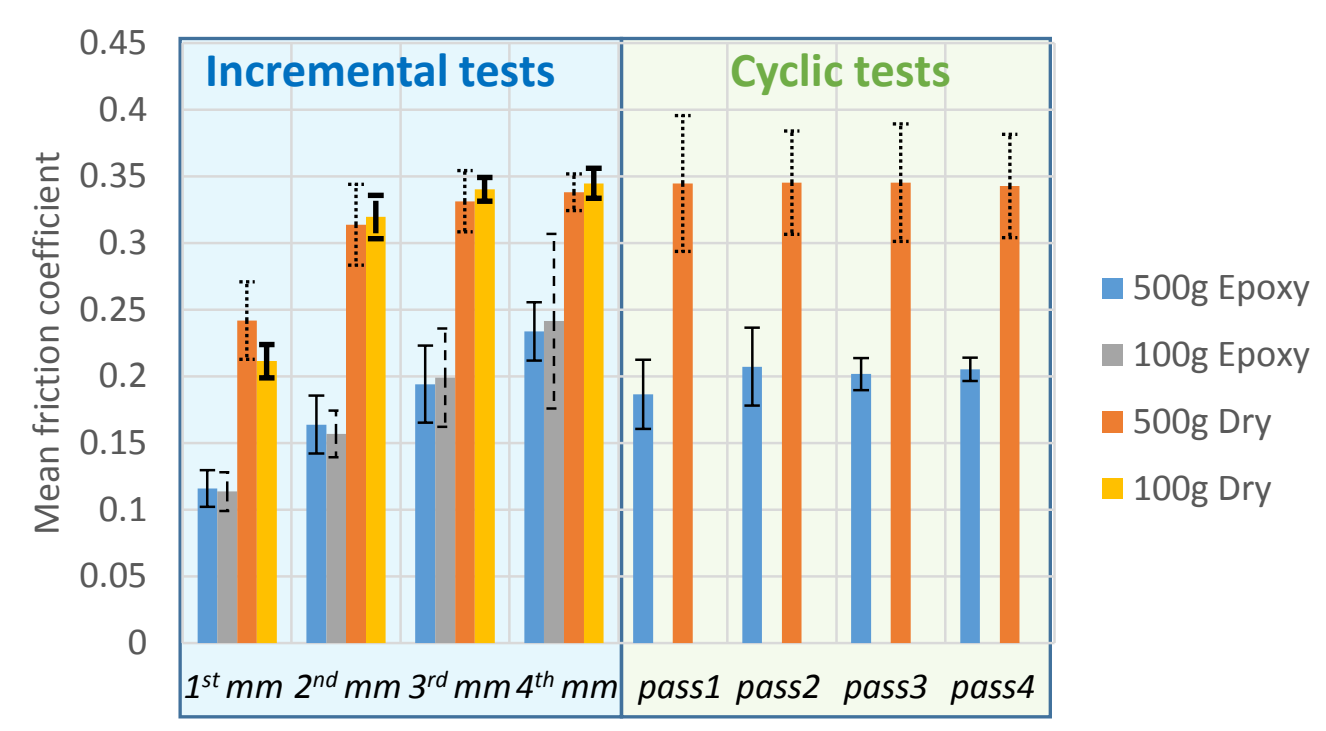




\section{Figs 9a-d}
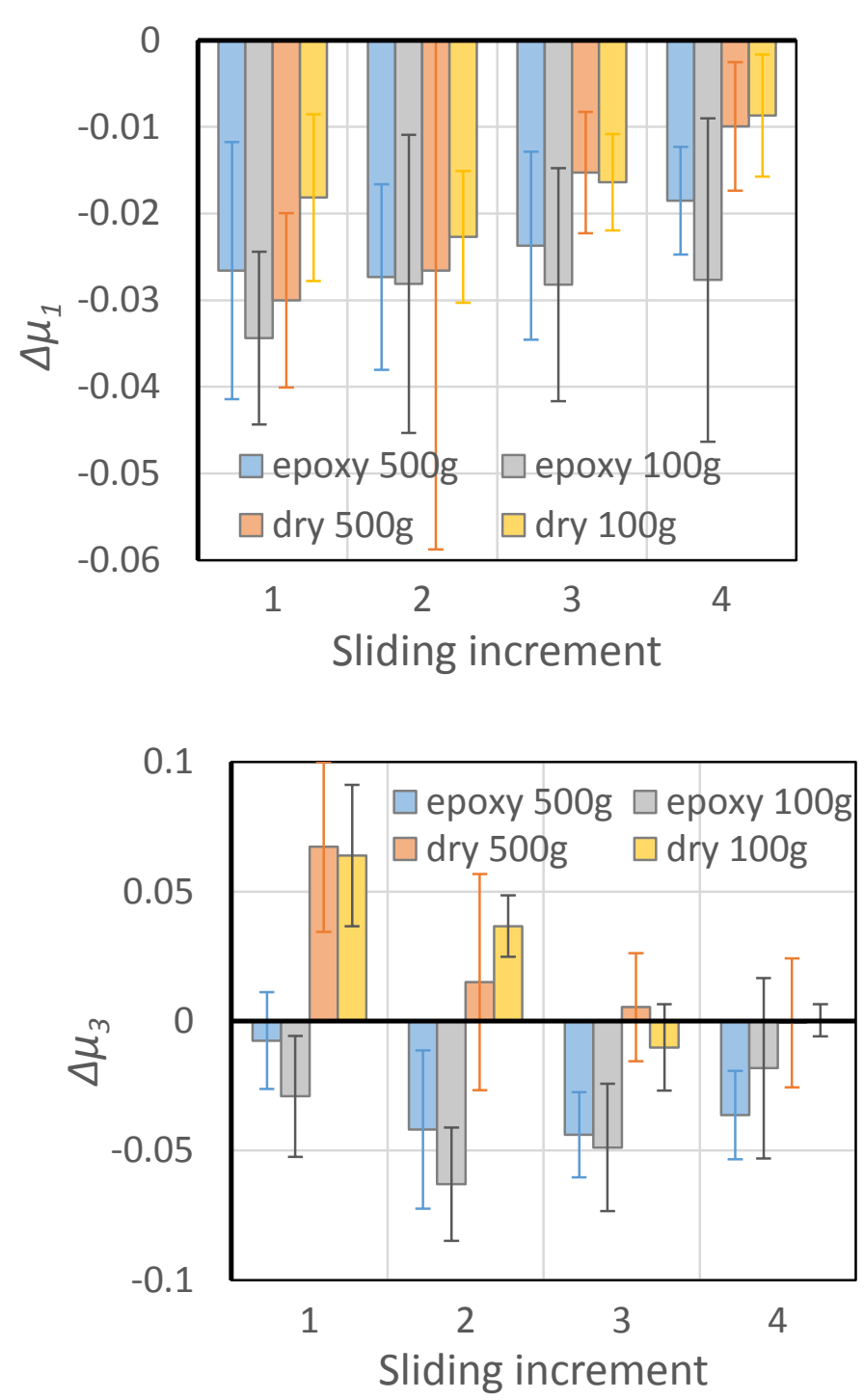
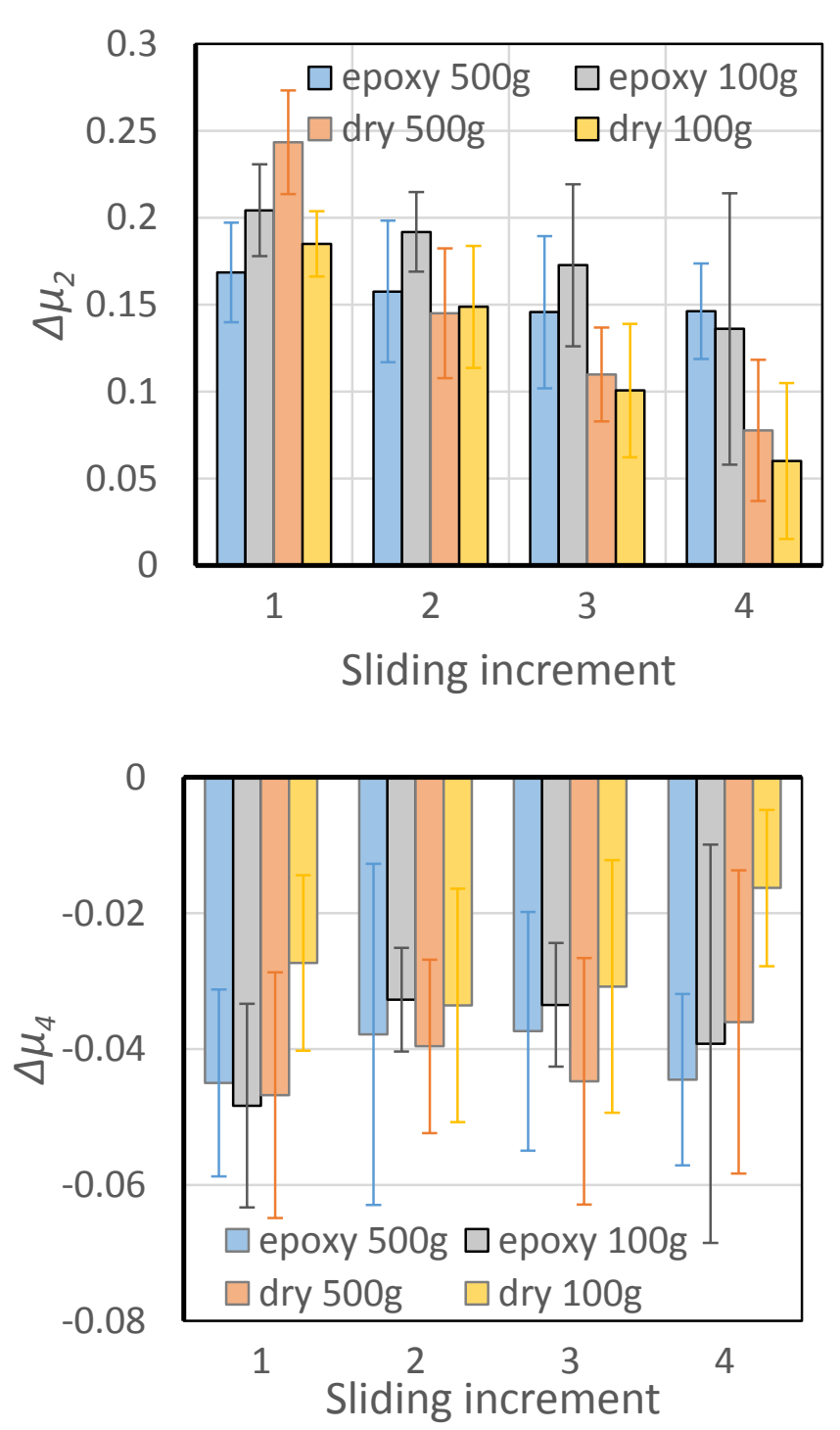
Figs $10 a, b$
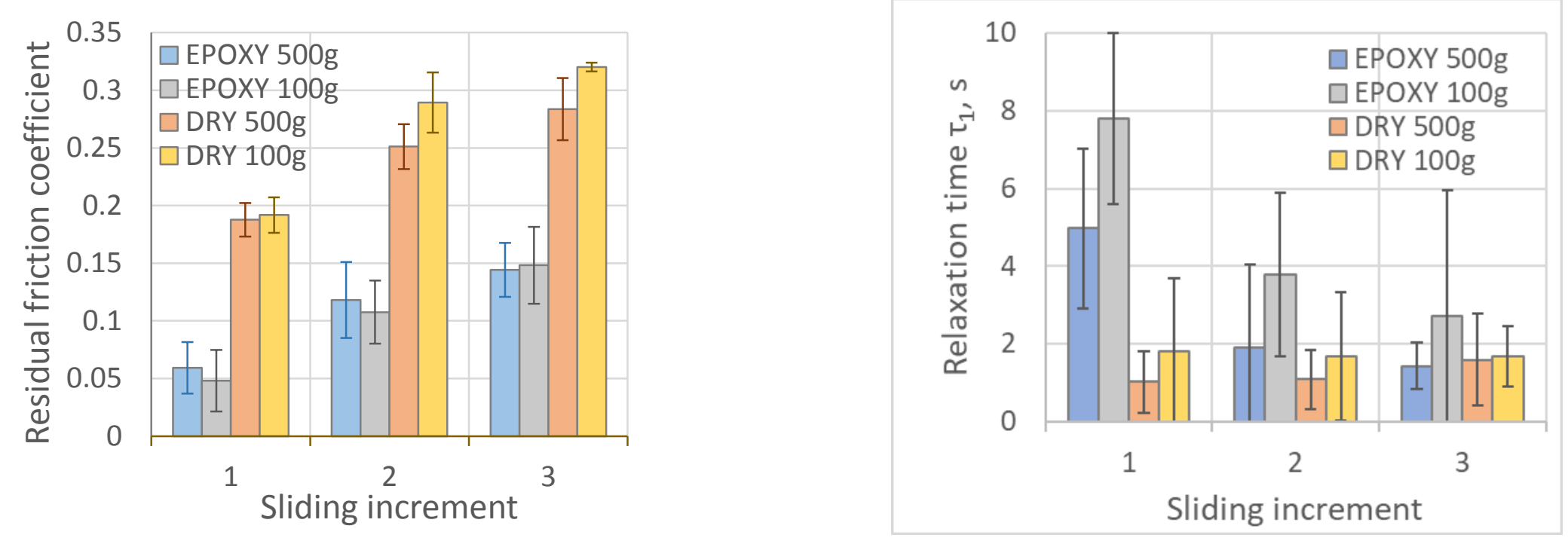


\section{Figs 11a-d}
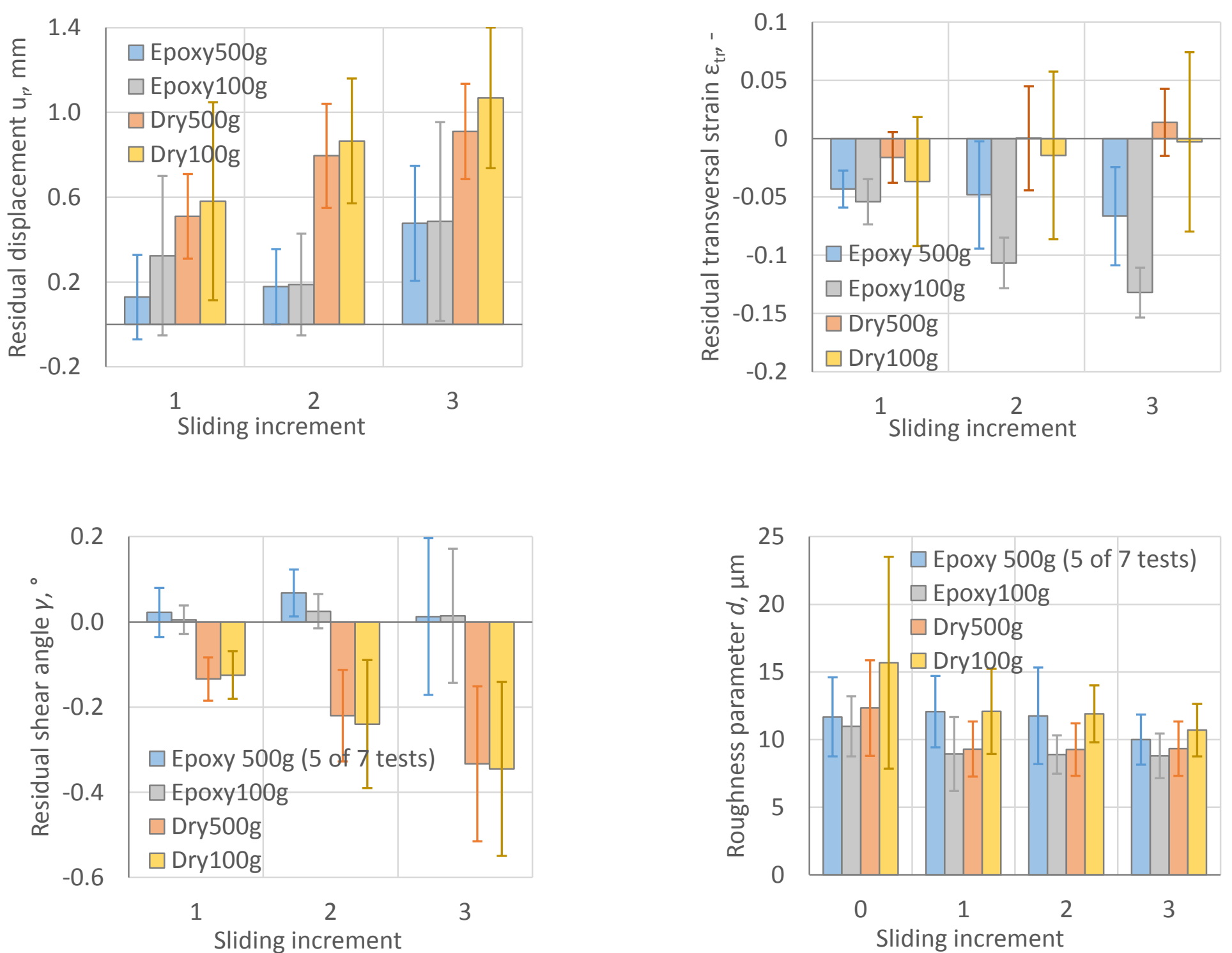